Ulil norden

\title{
Natural Capital in a Nordic context
}

Status and Challenges in the Decade of Biodiversity
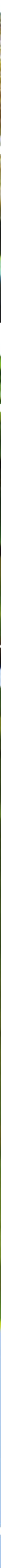

4 norden 



\section{Natural Capital in a Nordic context}

Status and Challenges in the Decade of Biodiversity

Leonardo Mazza, Marika Bröckl, Sanna Ahvenharju, Patrick ten Brink and Tiina Pursula,

Gaia Consulting Oy and Institute for European Environmental Policy (IEEP)

TemaNord 2013:526 
Natural Capital in a Nordic context

Status and Challenges in the Decade of Biodiversity

Leonardo Mazza, Marika Bröckl, Sanna Ahvenharju, Patrick ten Brink and Tiina Pursula,

Gaia Consulting Oy and Institute for European Environmental Policy (IEEP)

ISBN 978-92-893-2534-9

http://dx.doi.org/10.6027/TN2013-526

TemaNord 2013:526

(c) Nordic Council of Ministers 2013

Layout: Hanne Lebech/NMR

Cover photo: ImageSelect
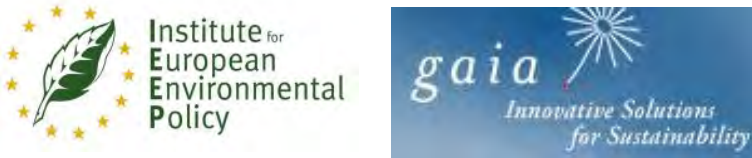

This publication has been published with financial support by the Nordic Council of Ministers. However, the contents of this publication do not necessarily reflect the views, policies or recommendations of the Nordic Council of Ministers.

www.norden.org/en/publications

\section{Nordic co-operation}

Nordic co-operation is one of the world's most extensive forms of regional collaboration, involving Denmark, Finland, Iceland, Norway, Sweden, and the Faroe Islands, Greenland, and Åland.

Nordic co-operation has firm traditions in politics, the economy, and culture. It plays an important role in European and international collaboration, and aims at creating a strong Nordic community in a strong Europe.

Nordic co-operation seeks to safeguard Nordic and regional interests and principles in the global community. Common Nordic values help the region solidify its position as one of the world's most innovative and competitive.

\section{Nordic Council of Ministers}

Ved Stranden 18

DK-1061 Copenhagen K

Phone (+45) 33960200

\section{www.norden.org}




\section{Content}

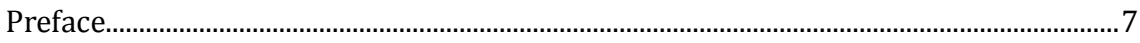

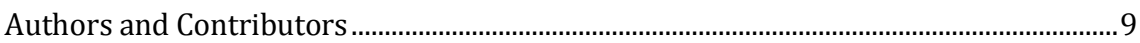

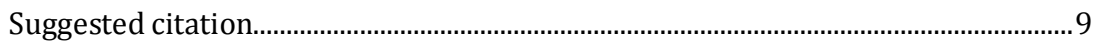

Acknowledgments ................................................................................................

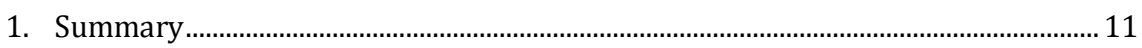

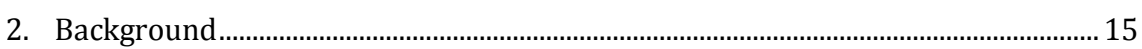

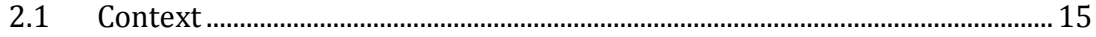

2.2 Goal of the study ................................................................................................ 27

2.3 Methodologies ...................................................................................................... 28

3. Five approaches to account for natural capital and biodiversity .............................29

3.1 The SEEA Central Framework (and WAVES as an approach

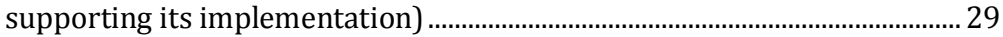

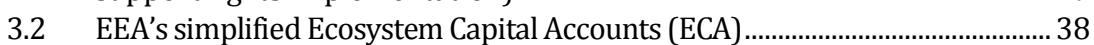

3.3 UK National Ecosystem Assessments (NEA) ……......................................... 41

3.4 Canada's Measuring Ecosystem Goods and Services (MEGS)........................ 49

3.5 Natural Capital Project - InVEST ………......................................................... 55

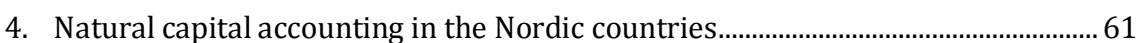

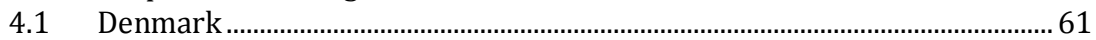

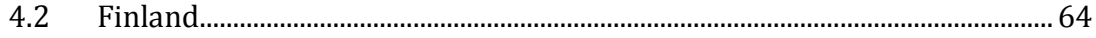

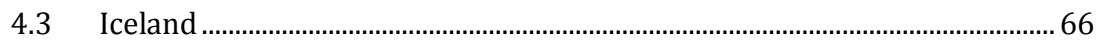

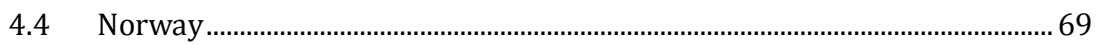

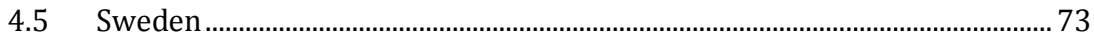

4.6 Summary of the Nordic needs and selected assessment criteria ................. 75

5. Analysis of biodiversity accounting systems in light of Nordic countries' needs......... 79

5.1 Presentation of the criteria in light of which the approaches were

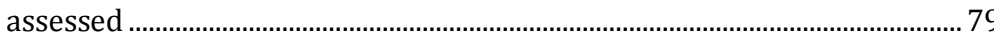

5.2 Synthesis assessment of the five approaches taking into account Nordic context ................................................................................................... 81

5.3 Short synthesis ........................................................................................... 95

6. Synthesis, roadmap and recommendations............................................................ 99

6.1 Policy context and needs of the Nordic countries........................................... 99

6.2 The approaches in the light of policy context and needs ..............................100

6.3 Roadmap and recommendations.......................................................................102

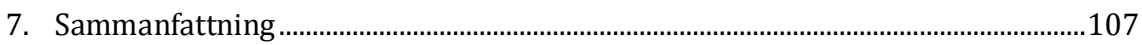

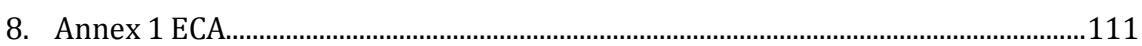





\section{Preface}

To address the root causes of environmental problems, their drivers and pressures need to be identified and understood. Climate change, pollution of air, water and soil, depletion of natural resources, overfishing, habitat destruction due to infrastructure development and introduction of alien species are some of the pressures on the environment which the Nordic countries face. In addition, as natural resources are becoming increasingly scarce, assessing the contribution of natural capital to the economy in a systematic and integrated way appears increasingly important. Both these agendas require a careful monitoring of the interlinkages between the economy and the environment.

We benefit from the many services provided by natural ecosystems. These ecosystem services are vital for our survival and for maintaining our quality of life. Services provided by ecosystems are for instance food, building materials, clean water and air, fuel etc. Cultural services provided by ecosystems are recreational services and an aesthetic environment. Additionally, ecosystems provide other types of vital services such as flood protection, maintaining soil quality, purifying water and air, pollination of crops - things we take for granted, but which are sensitive to environmental pressures and where biodiversity loss and deterioration of an ecosystem can have significant impact on the economy and our wellbeing. These types of services are often difficult to value, but valuation of these would help in policy making and follow-up of the implementation of policies. It can also make it easier to make decisions which concern for instance land use and prioritising of the protection of different types of ecosystems.

Like many other countries throughout the world, the Nordic countries have set themselves a range of targets in order to reduce or halt biodiversity loss. They are in different stages of planning of and incorporating natural capital into national accounting as well as in integrating natural capital into policymaking and follow-up of the impacts of policies. Ecosystems valuation and natural capital are relatively new concepts, at least in their practical application. Developing a practical exchange of ideas on good ways of including natural capital in policies and follow-up and finding standards for ecosystems valuation, which would apply in a Nordic context, is essential. 
This report reviews a selected range of international approaches for natural capital accounting. The five approaches reviewed are attempts to help create an improved evidence base on the links between biodiversity and ecosystems on the one hand and economic and human wellbeing on the other, in view of better informing decision-making in a variety of contexts.

The strengths and weaknesses of the approaches are evaluated in the light of the policy goals, institutions and conditions of the Nordic countries. This report provides suggestions on how the approaches could be used in the Nordic countries and presents a road map for application of the approaches. This may be particularly helpful for the Nordic countries when promoting Nordic policy solutions on the global framework arena concerning natural capital. biodiversity and valuation of ecosystem services. As seen in the report, from the climate change perspective, the issue of natural capital is of utmost importance. The Nordic countries will contribute with their expertise and experiences on the subject of how to interlink environment and economy.

The analysis was carried out during the period September 2012 - January 2013 by Gaia Consulting Oy and the Institute of European Environmental Policy. The project was commissioned by the Working Group on Environment and Economy and the Terrestrial Ecosystem Group under the Nordic Council of Ministers.

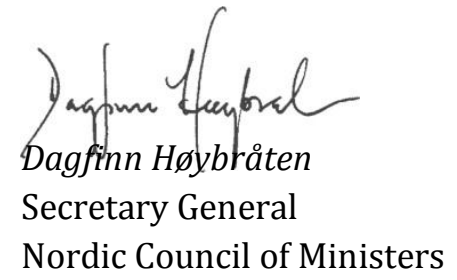




\title{
Authors and Contributors
}

\author{
Suggested citation
}

Mazza, L., Bröckl, M., Ahvenharju, S., ten Brink, P. and Pursula, T. (2013) Nordic capital in a Nordic context - Status and Challenges in the Decade of Biodiversity. A study prepared by Gaia Consulting Oy and the Institute for European Environmental Policy (IEEP) for the Nordic Council of Ministers, Copenhagen.

\section{Acknowledgments}

The authors of this report would like to thank the steering group (consisting of members from the Working Group on Environment and Economy, MEG, and the Terrestrial Ecosystem Group, TEG, under the Nordic Council of Ministers) for their valuable input and comments. The authors would also like to thank the following experts for their input and time: Jan-Erik Petersen (EEA), Ian Barrett (defra), Heather Tallis (Stanford University), Julian Harlow (defra), Rocky Harris (defra), Francois Soulard (Statistics Canada), Daniela Russi (IEEP), Sjoerd Schenau (Statistics Netherlands), Finn Katerås (Ministry of the Environment, Norway), Jessica Andersson (Swedish Environmental Protection Agency), Sigurdur Thrainsson (Ministry for the Environment, Iceland), Marina von Weissenberg (Ministry of the Environment, Finland), Eva Juul Jensen (Ministry of the Environment, Denmark), Jesper Tranberg (Ministry of the Environment, Denmark), Per Arild Garnåsjordet (Statistics Norway), Iulie Aslaksen (Statistics Norway), Leo Kolttola (Statistics Finland).

They have helped us understand the Nordic's needs and helped us refine our understanding on the different natural capital accounting approaches. 



\section{Summary}

This report evaluates the strengths and weaknesses of some of the most prominent international approaches to natural capital accounting in the light of the policy goals, conditions and institutions in the Nordic countries. The report does not, however, only review approaches that were developed for incorporation of biodiversity and ecosystems in national accounts, but takes a broader view.

The policies and targets related to biodiversity and monitoring of biodiversity are very similar in the Nordic countries. All countries have incorporated or have the ambition to incorporate the biodiversity and biodiversity accounting related Aichi targets in national policies and to set related targets in the NBSAPs that are being revised. All countries see it as a priority that indicators or accounts should be used as tools for policymaking. They should also be used in monitoring of how well the policies are implemented and targets are achieved both locally and nationally. All have an interest in developing ecosystems accounting and linking this to the economy and in developing methodologies for valuation of natural capital.

National level biodiversity accounting is in the initial stages of planning in most countries. Today, mostly stocks and flows of natural resources are monitored. The views expressed in interviews indicate that a good quality indicator and accounts system which monitors ecosystem values would be a desirable solution on a national level. However increased monetization and adjustment of GDP on a national level was not seen as a priority.

The international approaches which were selected for this study attempt to create an improved evidence base on the links between biodiversity and ecosystems on the one side and the economy and human well-being on the other side. The goal is to better inform decisionmaking in a variety of contexts. The five schemes selected for a more indepth analysis were: 
- The SEEA Central Framework (SEEA Volume 1).

- EEA's simplified Ecosystem Capital Accounts (ECA). ${ }^{1}$

- Canada's Measuring Ecosystems Goods and Services (MEGS).

- The UK National Ecosystem Assessment (UK NEA).

- Integrated Valuation of Ecosystem Services and Tradeoffs or InVEST.

All the schemes have the potential to generate information on some of the services provided by ecosystems, but each one of the systems approach the issue from a different angle and starting point. This results in different strengths and weaknesses when compared to the needs expressed by Nordic countries. ${ }^{2}$

Rather than overlap, all studied schemes contribute to an improved evidence base on the services provided by ecosystems and thus provide necessary information for decision-making and national accounting. The UK NEA looks into a very broad range of ecosystem service categories and a lot of resources have been invested in developing a better understanding of for instance the recreational value of nature. The SEEA Central Framework can mostly serve to capture a range of provisioning services but is not suited to capture regulating, supporting or cultural services. The main strength of the InVest tool, as things stand today, is its accounting of water related ecosystem services. The MEGS captures a broader spectrum of ecosystem services, but at a rather superficial level at present. The current ECA is stronger on carbon biomass, water and land use and their interactions.

Each one of the approaches is relevant for addressing at least some of the needs expressed by the policy-makers interviewed in the project. However, none of the approaches is really suited for monitoring biodiversity and, with the exception of the expected future ECA, for monitoring ecosystem quality and resilience.

It is essential to design effective biodiversity related policy that addresses the pressures and the drivers of biodiversity loss and thus to address some of the root causes behind the deterioration of ecosystems.

In order to implement the commitments relating to national capital accounting, the Nordic countries will in the next few years need to identify the areas where the development of accounts could be of particular importance and could support these goals.

${ }^{1}$ Specifically the approach to implementing the central framework promoted by the World Bank's WAVES project, which promotes the use of the central framework to incorporate natural capital into national accounts. 2 The needs of the Nordic countries are described in section 4 in detail. 
Out of the different approaches analysed in the context of this study, the UK National assessment seems to bear most potential to provide this kind of information and thus to respond to the Nordic countries' information needs. It has however weaknesses in key areas that would justify that the Nordic countries engage with each other of the approaches analysed in this study in some way or another. While the UK NEA-type approach appears one of the most useful in the short run and should help target further natural capital accounting efforts on areas of highest added value, the development of some of the other approaches in the short term appears unavoidable and indeed essential given broader benefits to policy making as a whole (e.g. SEEA Central Framework). Irrespectively of the approach chosen, the Nordic countries will need to invest in adapting them to their specific ecosystems and data availability.

It would also be useful to focus on making the underlying data compatible in order to make it possible to apply it in different contexts. The open source data thinking could be something which should be promoted in the Nordic countries as this could promote using the data for different purposes; for example provide it for companies needing to evaluate the risks and implications of their activities on the environment.

The Nordic countries should ideally cooperate in different areas. This is true especially for the more experimental and less mature approaches to natural capital accounting. It could perhaps be useful if there was a forum for cooperation on these issues - a Nordic group of experts specialised in ecosystems accounting to draw a roadmap for the future, regularly meet and share experiences and relevant information. This would be especially useful for those countries which are in the initial stages on assessing how to include nature values into national accounting. 



\section{Background}

\subsection{Context}

Like many other countries throughout the world, the Nordic countries have set themselves a range of targets in order to reduce or halt biodiversity loss. To address root causes of environmental problems, their drivers and pressures need to be identified and understood. In addition, as natural resources are becoming increasingly scarce, assessing the contribution of natural capital to the economy in a systematic and integrated way appears increasingly important. Both these agendas require a careful monitoring of the inter linkages between the economy and the environment. The World Bank, the UN Statistics Commission, the United Nationas Environment Programme (UNEP) and the OECD are only some of the many international organizations which have highlighted in recent years that more detailed accounts are needed to better manage our economies given that, at the macro-economic level, development can be seen as a process of building wealth and managing a portfolio of capital, including natural capital in its various forms.

The Nordic countries are involved in a range of processes aiming to integrate natural capital in their national accounting framework. These processes include in particular:

- The UN Statistical Commission's efforts to develop the System of Environmental-Economic Accounts (SEEA), including efforts on developing Experimental Ecosystem Accounts.

- The EU regulation No 691/2011 on European environmental economic accounts (to be implemented by EU Member States).

- The CBD Aichi Strategic Plan 2011-2012, whose Target 2 calls for the incorporation of the values of biodiversity in national accounting and reporting systems.

- EU's Biodiversity Strategy, which in its Action 5 foresees that Member States, with the assistance of the Commission, will "map and assess the state of ecosystems and their services in their national territory by 2014 , assess the economic value of such services, and promote the integration of these values into accounting and reporting systems at EU and national level by 2020." 
- EEA's efforts to develop ecosystem capital accounts, including by working on a simplified Ecosystem Capital Accounts (ECA).

All Nordic countries are parties to the Convention on Biological Diversity (CBD) and are currently in the process of revising their National Biodiversity Strategies and Action Plans (NBSAPs). The five countries have also been active in the Rio +20 process which led to renewed commitments to halt biodiversity loss. In addition, fifty-seven countries (including Denmark, Finland, Norway and Sweden) and the European Commission expressed their support to a communiqué calling on governments, the UN system, international financial institutions and other international organizations to strengthen the implementation of natural capital accounting around the world and factor the value of natural assets like clean air, clean water, forests and other ecosystems into countries' systems of national accounts. ${ }^{3}$

Norway is also part of the World Bank-led WAVES (Wealth Accounting and the Valuation of Ecosystem Services) initiative, and has been a leader in the area of developing environmental economic accounting. The value of biodiversity and ecosystems has historically been largely "invisible" in decision-making. This invisibility is seen as one important driver behind the degradation of ecosystems and the loss of biodiversity. ${ }^{4}$ As highlighted in Box 1 below, the TEEB initiative and the series of publications and reports that it has led to has recently drawn much attention on the wide range of values that are derived from biodiversity and ecosystems and the ways in which these could be better accounted for in policy-making.

\footnotetext{
3 http://www.wavespartnership.org/waves/sites/waves/files/images/NCA_list_of_supporters.pdf 4 ten Brink P., Mazza L., Badura T., Kettunen M. and Withana S. (2012) Nature and its Role in the Transition to a Green Economy.
} 
Box 1: The TEEB (The Economics of Ecosystem and Biodiversity) - Initiative: context and outputs

In 2007, environment ministers from the governments of the G8+5 countries, meeting in Potsdam, Germany, agreed to "initiate the process of analysing the global economic benefit of biological diversity, the costs of the loss of biodiversity and the failure to take protective measures versus the costs of effective conservation."

The Economics of Ecosystems and Biodiversity (TEEB) study, which emerged from that decision, has delivered a series of reports addressing the needs of major user groups: national and local decision makers, business and the wider public. Those studies, as well as a TEEB Synthesis report, are all downloadable from the TEEB website (see link below).

The analysis of TEEB builds on extensive work in the field of economics of ecosystem and biodiversity over the last decades. While acknowledging the plurality of values which people hold for nature, as well as the multitude of techniques available for their assessment, the TEEB presents an approach that can help decision makers recognize, demonstrate and, where appropriate, capture the values of ecosystems and biodiversity.

- More information on the TEEB initiative and related publications can be found on: http://www.teebweb.org/

The quasi systematic "under-pricing" and "undervaluing" of natural capital, as illustrated in a wide range of examples across the TEEB reports, has also made it difficult to design appropriate policies for ensuring that income or profits from the use of natural capital are reinvested into the sustainable management/restoration or other productive assets. ${ }^{5}$ This is due to a lack of awareness of these values as well as the absence of decision-making tools that may adequately account for the value of ecosystems and/or reveal the impact of specific economic activities on ecosystems and biodiversity. It has also been made difficult by the absence of enough information and data on ecosystems and biodiversity in a format that would facilitate its consideration in decision-making processes and tools (e.g. cost-benefit analysis).

At the conceptual level, the concept of natural capital has proved useful in underlining the importance of ecosystems and biodiversity to the

${ }^{5}$ Barbier E. (2002) “The Role of Natural Resources in Economic Development," 2002 Joseph Fisher Lecture, Adelaide University, Adelaide, Australia, September 30, 2002. 
economy. It has drawn attention to the fact that nature, in providing a series of services that benefit society and the economy, can be understood as providing natural assets, which are increasingly referred to as "natural capital."6 Natural capital stocks provide flows of ecosystem services. The analogy with other forms of capital (See Box 2), such as manufactured and financial capital, has helped to highlight the role of nature in the economy. It has also been useful for underlining the loss of natural capital and in exploring the underlying causes of its unsustainable use and management.

\section{Box 2: The different types of capital 7,8}

Manufactured or "man-made" capital: This includes produced assets that are used to produce other goods and services, such as machines, tools, buildings and infrastructure - i.e. fixed assets. This category can also include money and other financial assets that are sometimes termed financial capital. "Financial capital" is sometimes seen as a distinct category of capital (Aronson et al. 2007 and Van Andel \& Aronson, 2012).

Human capital: This generally refers to the health, well-being and productive potential of individual people and includes mental and physical health, education, motivation, and work skills. These elements not only contribute to a happy and healthy society, but also improve the opportunities for economic development through a productive workforce.

Social capital: Like human capital, this is related to human well-being but on a societal rather than individual level. It consists of the social networks that support an efficient, cohesive society and facilitate social and intellectual interactions among its members. Social capital refers to those stocks of social trust, norms and networks that people can draw upon to solve common problems and create social cohesion, e.g. neighbourhood associations, civic organizations and cooperatives. The political and legal structures that promote political stability, democracy, government efficiency and social justice are also part of social capital. Thus the elements of social capital are central factors of productivity as well as being desirable in themselves.

\footnotetext{
${ }^{6}$ Barbier E. (2011) Capitalizing on Nature - Ecosystems as Natural Assets, Cambridge University Press. 7 TEEB (2011), The Economics of Ecosystems and Biodiversity in National and International Policy Making. Edited by Patrick ten Brink. Earthscan, London and Washington.

8 GHK, IEEP, PSI, et al (2005) 'SRDTOOLS Methods and tools for evaluating the impact of cohesion policies on sustainable regional development (SRD)', Contract No 502485 Sixth Framework Programme Priority 8.3.1 Task 11 Regio Underpinning European Integration, Sustainable Development, Competitiveness and Trade Policies building on Pearce, D.W., Markandya, A. and Barbier, E. (1989) Blueprint for a Green Economy, Earthscan, London and Ekins, P. (1992) "A four-capital model of wealth creation," in P. Ekins and M. Max-Neef (eds) RealLife Economics: Understanding Wealth Creation, Routledge, London and New York, pp147-155.
} 
Natural capital: In addition to natural resources (like timber, water, and energy) and mineral reserves, natural capital includes natural assets that are not easy to value monetarily (e.g. species diversity, endangered species, ecosystems that per-form ecological services like air and water filtration) and can be considered as the components of nature linked directly or indirectly to human welfare. Forests, agri-cultural land and soil, grasslands, wetlands, rivers and coral reefs are examples of natural capital.

\section{Better consideration of natural capital in decision-making}

At the practical level there is a number of different approaches to promote and facilitate the consideration of natural capital (i.e. ecosystems and biodiversity and the services they deliver) in decision-making and more specifically to help better integrate and incorporate the value of natural capital in economic decision-making frameworks and the system of national accounts ${ }^{9}$ (i.e. macro-economic monitoring and analysis). Five of these approaches were selected for further analysis in this study (see section 2.2.).

The reason why natural capital "accounts" are generally considered central to incorporating nature and ecosystem's values in decisionmaking is that they are expected to provide a bedrock for consistent, comparable statistics and indicators, thus allowing to bring together within a coherent framework the data needed to produce policyrelevant analysis of the relationships between the economy and the environment and more specifically the impacts on the environment of specific policy decisions. In particular integrated environmental-economic accounting has the potential to help make actual or potential trade-offs of policy-maker's and manager's decisions affecting natural resources and associated services explicit. ${ }^{10}$

The figure below, produced to illustrate the role and the added value of environmental-economic accounts, shows how statistics, accounts and indicators are broadly linked.

\footnotetext{
${ }^{9}$ The System of National Accounts (SNA) is the internationally agreed standard set of recommendations on how to compile measures of economic activity. The SNA describes a coherent, consistent and integrated set of macroeconomic accounts in the context of a set of internationally agreed concepts, definitions, classifications and accounting rules. For more information visit the unstats webpage: http://unstats.un.org/unsd/nationalaccount/sna.asp 10 UN Statistics Commission's brochure on SEEA: http://unstats.un.org/unsd/envaccounting/Brochure.pdf
} 
Figure 1: Information pyramid and dedicated audience of environmentaleconomic accounts

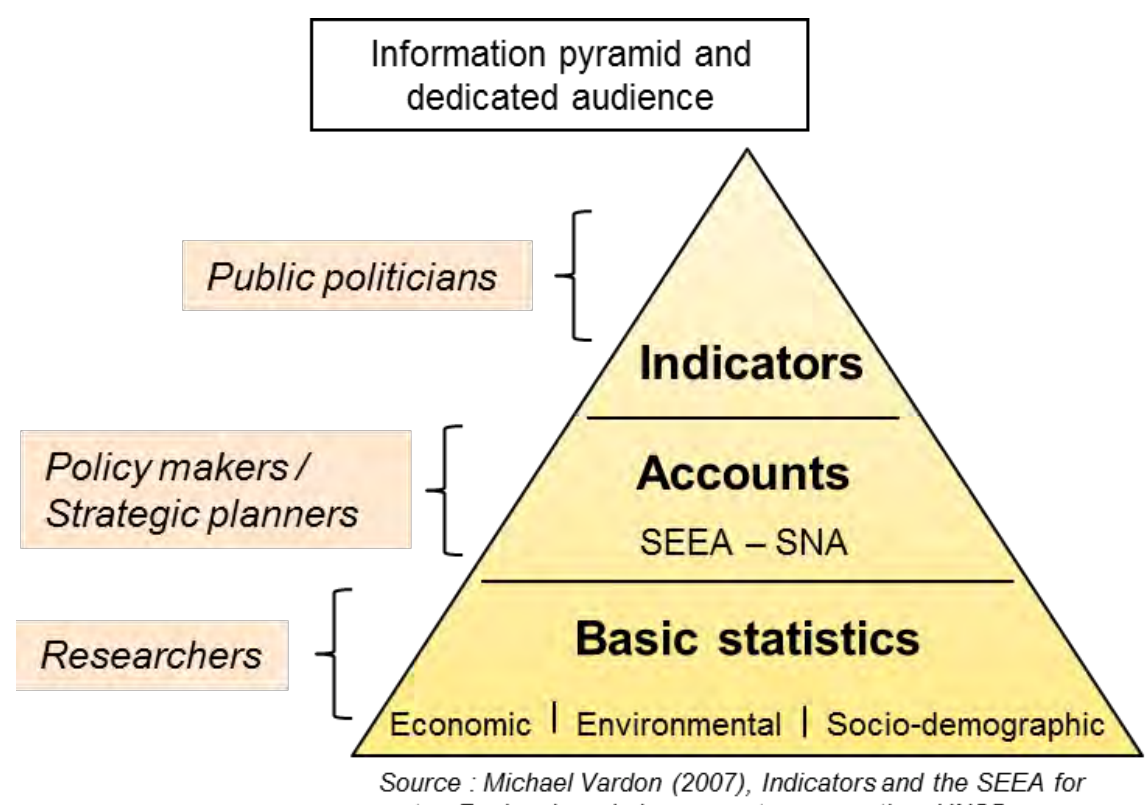

Figure 1 may also help highlight one of the major difficulties in developing natural capital accounts duly taking into account the value of natural assets. Some environmental accounts are relatively straightforward to produce and rest on data and statistics that have been collected for a long time in many European countries. These include for examples:

- Environmental accounts expressed in physical terms such as air emission accounts (including greenhouse gases), economy-wide material flow accounts, energy accounts, water accounts.

- Environmental accounts expressed in monetary terms such as environmental taxes, environmental protection expenditure, environmental subsidies, environmental goods and services sector, etc.

- Asset accounts such as forestry accounts, natural resource accounts for oil and gas.

Other natural capital accounts relating to ecosystems and biodiversity are currently still much more challenging to produce and rely heavily on new data collection and calibration exercises that have only recently been initiated in many countries. Many of them call for extensive data collection exercises involving ecosystem assessments and on different 
approaches to valuation (where economic accounts are to be expressed in monetary terms). In particular in the area of ecosystem services, there are still significant data gaps and significant methodological challenges involved in producing accounts meeting high statistical standards. It must be acknowledged, however, that significant progress has been made in estimating the values derived from biodiversity and ecosystems ${ }^{11}$ and that these should be acknowledged as important steps forward towards more fully incorporating biodiversity and ecosystems in national accounting frameworks in order to develop better understanding of the linkages between biodiversity and ecosystems on the one hand and the economy on the other hand and develop appropriate indicators and policy responses.

The purpose of environmental-economic accounting is indeed generally considered to be:

- Monitoring the transition to sustainable development (a need identified in Agenda 21).

- Collection of more statistical evidence to inform policy.

- Overcome the isolation of different kinds of statistics (e.g. environmental, economic, etc.); provide indicators that directly respond to the demand of integrated policy-making.

- Obtain measurement of the crucial role of the environment as a source of natural capital and as a sink of by-products (e.g. pollution) generated during the production of man-made capital and other human activities.

Indicators derived from the SEEA (System of Environmental-Economic Accounts) should allow the following questions to be answered:

- On which resources does the country depend most and how efficiently are these resources being used?

- Who benefits (which sectors) from natural resource use?

- What are the impacts of resource use and pollution on the state of the environment? 
- How does depletion of natural resources affect measures of the real income of a nation? To what extent are the depletion costs recovered by the government?

- Are current trends in production and consumption of resources sustainable? What is the impact of policy instruments introduced?

Depending on the information and data systematically collected through other approaches, a range of questions relating more directly to ecosystems, biodiversity and the services they provide could be investigated and monitored. Box 3 below provides the definitions of and explains the interrelations between a range of key concepts in the field of biodiversity and ecosystems that are also frequently used in the context of natural capital accounting and therefore throughout this report.

\section{Box 3: Key concepts and terms glossary}

Biological diversity or Biodiversity means 'the variability among living organisms from all sources, including terrestrial, marine and other aquatic ecosystems and the ecological complexes of which they are part; this includes diversity within species, between species and of ecosystems' ${ }^{\prime}$. The term covers every form of life on earth (plants, animals, fungi and micro-organisms), the diversity of communities that they form and the habitats in which they live. It encompasses three levels: ecosystem diversity (i.e. variety of ecosystems); species diversity (i.e. variety of different species); and genetic diversity (i.e. variety of genes within species).

Ecosystem means 'a dynamic complex of plant, animal and micro-organism communities and their non-living environment interacting as a functional unit' (ibid.). Every ecosystem is characterized by complex relationships between living (biotic) and non-living (abiotic) components (resources), sunlight, air, water, minerals and nutrients. The quantity (e.g. biomass, productivity), quality and diversity of species (e.g. richness, rarity) all play an important role. The functioning of an ecosystem often hinges on certain species or groups of species that perform key functions e.g. pollination, grazing, predation, or nitrogen-fixing.

Ecosystem services refer to the flow of benefits that people obtain from ecosystems (MA, 2005). These include:

- $\quad$ rovisioning services (e.g. food, fibre, fuel, water);

- regulating services (benefits arising from ecosystem processes that regulate climate, pollination, natural hazards such as flooding, spread and outbreak of diseases, waste, air and water quality);

- cultural services (e.g. recreation, tourism, and aesthetic, spiritual and ethical values); 
- supporting services (e.g. soil formation, photosynthesis, nutrient cycling; ${ }^{1}$ necessary for sustaining almost all other ecosystem services).

- Further to the classification above, 'habitat services' can also be recognised as a separate category of ecosystem services to highlight the importance of ecosystems to provide habitats for migratory species (e.g. as nurseries) and as gene pool 'protectors' (maintain gene pool diversity and vitality) ${ }^{1}$.

In more economic terms, it can be said that ecosystem services flow from 'natural capital stocks' (also sometimes termed 'natural assets'), like interest or dividends from the financial stocks.

Building on the representation of the relationship between ecosystem services and human wellbeing developed in the context of the Millennium Ecosystem Assessment (ibid.), the figure below depicts the role of natural capital in this process. The flow of ecosystem services - provisioning, regulating and cultural services can provide direct and indirect support for livelihoods (food, materials, water, jobs), security (food, climate, and natural disasters), health (via clean water, disease control, medicines) and community well-being (ibid.; see Figure 2 below) Natural capital plays an essential role in the provision of these services as it underpins both the functioning of ecosystems, as well as other forms of capital.

Figure 2: Contribution of natural capital to human well-being and livelihoods

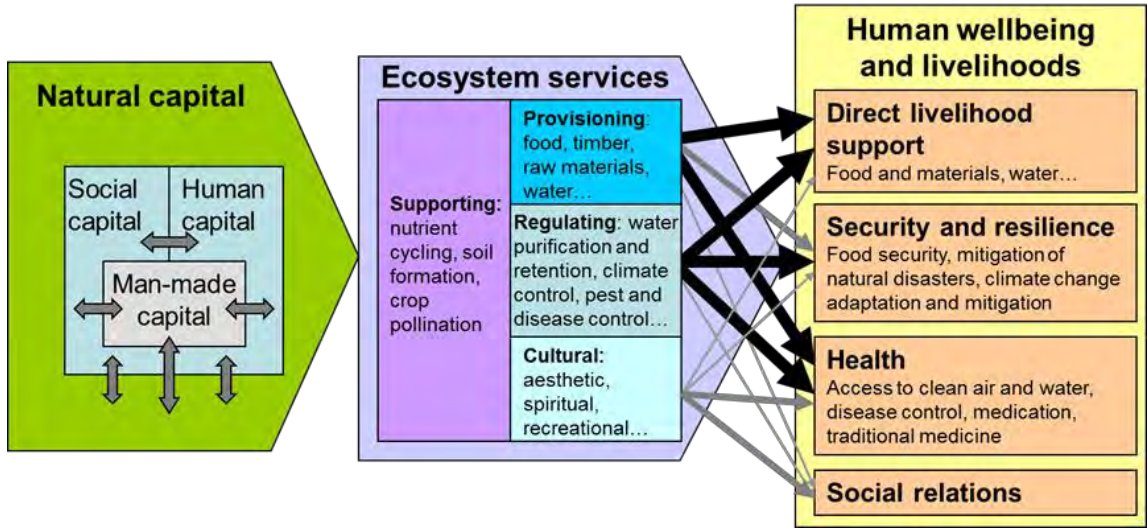

Source: Own Representation Laure Ledoux, building on MA (Millennium Ecosystem Assessment) (2005) www.maweb.org/en/index.aspx and TEEB (2011), The Economics of Ecosystems and Biodiversity in National and International Policy Making. Edited by Patrick ten Brink. Earthscan, London and Washington 
In addition to the above concepts that are primarily rooted in ecology and more generally natural sciences, this report also uses a number of terms that are commonly used in the social sciences, more specifically by the statistical community and in policy-making. These are briefly reviewed and defined in Box 4 below.

\section{Box 4.: Statistics, indicators and accounts: key definitions}

Statistics are numerical data relating to an aggregate of individuals; the science of collecting, analysing and interpreting such data. In different languages, the word used to refer to 'statistics' might be more or less broad.

In the context of policy-making, an indicator can be defined as "a measure based on verifiable data that conveys information about more than itself" ${ }^{\prime 1}$. This means that indicators are purpose-dependent - the interpretation or meaning given to the data depends on the purpose or issue of concern. According to a definition by IIED, "an indicator quantifies and simplifies phenomena and helps us understand complex realities. Indicators are aggregates of raw and processed data but they can be further aggregated to form complex indices". Since indicators are measures of something, they can usually be presented in a numerical or quantitative form.

The general term 'biodiversity indicators' as used in this report and by the Convention on Biological Diversity (CBD) covers more than direct measures of biodiversity itself, such as species populations and extent of ecosystems. It also covers actions to ensure biodiversity conservation and sustainable use, such as the creation of protected areas and regulation of the harvesting of species, and pressures or threats to biodiversity such as habitat loss. Biodiversity indicators can also be simple measures or more complex indices. ${ }^{1}$

Good indicators should be policy relevant, scientifically sound, easily understood, pratical, affordable and sensitive to relevant changes (CBD; TEEB Foundations (2010) Chapter3).

An account typically is a tool which records, for a given aspect of economic life, (a) the uses and resources or (b) the changes in assets and the changes in liabilities and/or (c) the stock of assets and liabilities existing at a certain time. Transaction accounts include a balancing item which is used to equate the two sides of the accounts (e.g. resources and uses) and which is a meaningful measure of economic performance in itself.

An ecosystem account is an account that describes the stocks of various categories of ecosystems and the changes in these stocks. The development of ecosystem accounts aims for example to measure the state of ecosystems and their 
capacity to provide ecosystem services and could ultimately also allow to calculate the costs of avoiding or repairing damage. Ecosystem Capital Accounts (ECA) are being developed to extend the scope of environmental accounting - the ultimate objective being to measure the ecosystem services that do not directly enter the economy and do not have a market price (see box 2 above).

Sources: OECD glossary of statistical terms; EEA; BIP Guidance for National Biodiversity Indicator Development and Use (2011).

In the pursuit of targets in the area of biodiversity policy, whether those involve the development and implementation of biodiversity policy or the integration of biodiversity related aspects in other sector's policies, decision-makers increasingly demand biodiversity and ecosystem related data and indicators that can be integrated into the relevant level of policy-making (regional, national, sub-national, local) as well as taken into account across a wider range of policy-areas.

Biodiversity and ecosystem service indicators can be useful across different sectors and at different stages of the policy cycle. ${ }^{12}$ They can be applied to:

- Problem recognition (e.g. endangered habitats and loss of ecosystem services).

- Identification of solutions (e.g. management activities for favourable conservation status).

- Assessing and identifying linkages between policy options (e.g. investment in protected areas, green infrastructure).

- The implementation process (e.g. subsidy reform, payment for ecosystem services).

- Ongoing monitoring and evaluation (e.g. status and trends).

To make full use of their potential, indicators should be part of an analysis framework that addresses functional relationships between nature and human wellbeing, such as the widely used DPSIR (drivers, pressures, status, impact and responses) approach (see figure 3 below).

12 TEEB (2011), The Economics of Ecosystems and Biodiversity in National and International Policy Making. Edited by Patrick ten Brink. Earthscan, London and Washington. 
Figure 3: The Pathway from Drivers to Impacts ${ }^{13}$

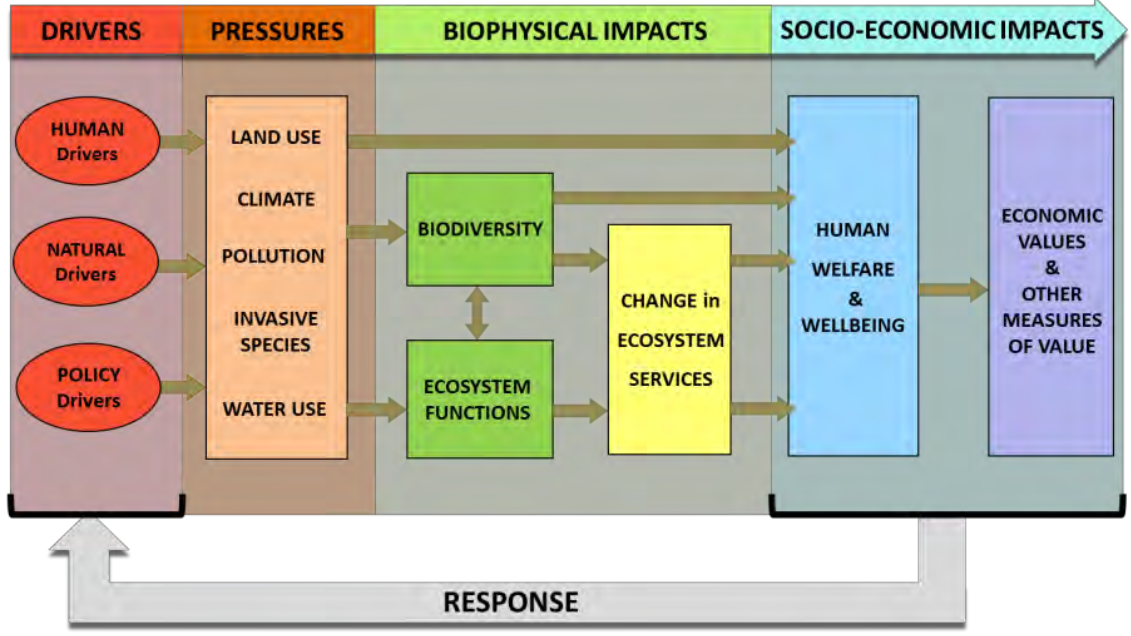

Source: adapted by authors from TEEB, 2011a and Braat et al., 2008.

The DPSIR framework makes it possible to characterize and measure driving forces (e.g. population growth, consumption and production patterns), pressures on biodiversity state and ecosystem functions (e.g. intensive agriculture, climate change), their impact on the delivery of ecosystem services and on human well-being and, finally, the policy response. ${ }^{14}$ Figure 3 above presents a simplified illustration of the interconnections between the conditions or states of ecosystems. It shows functions and service flows; the drivers affecting the state, functions and flows; the benefits that people, society and the economy gain from nature and tools to value these benefits.

Section 3 of this report presents five different approaches to natural capital accounting that were developed in response to the various demands of policy-makers.

\footnotetext{
${ }^{13}$ Source: ten Brink P., Mazza L., Badura T., Kettunen M. and Withana S. (2012) Nature and its Role in the Transition to a Green Economy, adapted from TEEB (2011), The Economics of Ecosystems and Biodiversity in National and International Policy Making. Edited by Patrick ten Brink. Earthscan, London and Washington; and Braat, L. and ten Brink, P. (eds) with Bakkes, J., Bolt, K., Braeuer, I., ten Brink, B., Chiabai, A., Ding, H., Gerdes, H., Jeuken, M., Kettunen, M., Kirchholtes, U., Klok, C., Markandya, A., Nunes, P., van Oorschot, M., Peralta-Bezerra, N., Rayment, M., Travisi, C. and Walpole, M. (2008) The Cost of Policy Inaction (COPI): The Case of Not Meeting the 2010 Biodiversity Target A report for the European Commission, Brussels. 14 TEEB (2011), The Economics of Ecosystems and Biodiversity in National and International Policy. Making. Edited by Patrick ten Brink. Earthscan, London and Washington.
} 


\subsection{Goal of the study}

The Nordic Council of Ministers (NCM) wishes to evaluate the strengths and weaknesses of some of the most prominent international approaches to natural capital accounting in the light of the policy goals, policies, conditions and institutions in the Nordic countries. Given the broad spectrum of policy goals, policies and conditions in the Nordic countries, the report does not exclusively review approaches that were developed in view of facilitating the incorporation of biodiversity and ecosystems in national accounts. The five approaches selected primarily have in common that they are attempts to help create an improved evidence base on the links between biodiversity and ecosystems on the one side and the economy and human well-being on the other side in view of better informing decision-making in a variety of contexts.

The five schemes selected for a more in-depth analysis in the context of this project are:

- The SEEA Central Framework (SEEA Volume 1) and specifically the approach to implementing the central framework promoted by the World Bank's WAVES project, which promotes the use of the central framework to incorporate natural capital into national accounts.

- EEA's simplified Ecosystem Capital Accounts (ECA) work, which currently is focused on developing ecosystem capital accounts for Europe.

- Canada's Measuring Ecosystems Goods and Services (MEGS) project.

- The United Kingdom's National Ecosystem Assessment (UK NEA).

- The Natural Capital Project's computer-based model InVest ("Integrated Valuation of Ecosystem Services and Tradeoffs") (Stanford University, the WWF and the Nature Conservancy).

It is worth highlighting upfront that it is unlikely that one of the above approaches alone suffices to respond to the variety of needs the Nordic countries may have. Interviews with officials have indeed unveiled a great variety of expectations and needs, ranging from quite common to more specific ones, across the different countries. Thus, the aim of the research project has rather been to:

- Identify, for each one of the approaches, which needs it may address and which policy questions it might help answer.

- Identify where the different approaches overlap and/or are complementary.

- Which needs might not be covered by any of the approaches. 
In addition, clarifying the above aspects is expected to contribute to supporting some of the Nordic's 2009-2012 Environmental Action Plan's priority objectives, in particular:

A. The overall objective to achieve a sustainable management of the natural environment for the purpose of protecting natural processes and the value of the cultural landscape to maintain ecosystem services.

B. The overall objective that consumption and production takes place in a manner that environmental and health conditions can be improved and resource utilisation is efficient and sustainable.

\subsection{Methodologies}

The specificities of the selected schemes/approaches are highlighted in overviews prepared for each one of the five systems. These were put together on the basis of desk studies but also benefitted from details provided by a range of interviewees with a specific expertise on one of the approaches studied in the project.

Furthermore, the suitability of the five approaches for responding to the different needs of the Nordic countries was assessed. The needs of the Nordic countries have mainly been derived from a targeted desk study focused on the country's main commitments and targets in the area of nature conservation as well as semi-structured interviews with CBD focal points and people responsible for biodiversity accounting development in the national statistical bureaus. This information, together with more generic criteria for assessing the quality of indicators and statistics, such as the RACER evaluation framework, ${ }^{15}$ formed the basis for the development of criteria against which the approaches were assessed. The evaluation of the five approaches involved interviews with at least one expert per approach. The results of this work are presented in sections 3-7 below.

15 RACER stands for Relevant, Accepted, Credible, Easy and Robust. 


\section{Five approaches to account for natural capital and biodiversity}

The five approaches presented below, chosen together with the project's steering group, ${ }^{16}$ are thought to be broadly representative of the different angles from which an improvement of natural capital accounting can be approached. While they have not all reached full maturity yet, they should in principle all generate information that can be used to improve the understanding of the links between the economy and human well-being on the one hand and biodiversity and ecosystems on the other hand, thus allowing for a better consideration of such links in decision-making.

\subsection{The SEEA Central Framework (and WAVES as an approach supporting its implementation)}

\subsubsection{Summary}

The System of Environmental-Economic Accounts (SEEA) contains the internationally agreed standard concepts, definitions, classifications, accounting rules and tables for producing internationally comparable statistics on the environment and its relationship with the economy. The SEEA framework follows a similar accounting structure as the System of National Accounts (SNA) and uses concepts, definitions and classifications consistent with the SNA in order to facilitate the integration of environmental and economic statistics.

The SEEA main purpose in a policy-making context is to serve as a system for organizing statistical data for the derivation of coherent indicators and descriptive statistics to monitor the interactions between the

16 Eli Moen, Fredrik Granath, Øyvind Lone, Mats Ekanger, Ola Yndeheim, Ólafur A Jónsson, Outi.Honkatukia and Maria Vuorelma. 
economy and the environment and the state of the environment to better inform decision-making. It also serves as an organising framework for an integrated system of stocks and flow accounts that measure interactions between the economy and the environment and the quality of environmental assets.

The SEEA does not propose any single headline indicator. Rather it is a multi-purpose system that generates a wide range of statistics and indicators with many different potential analytical applications. It is a flexible system in that its implementation can be adapted to countries' priorities and policy needs while at the same time providing a common framework and common concepts, terms and definitions.

WAVES (Wealth Accounting and the Valuation of Ecosystem Services) is a global partnership led by the World Bank that aims to promote sustainable development by ensuring that the national accounts used to measure and plan for economic growth include the value of natural resources. It is dedicated to the building of capacities in countries to establish environmental accounts based on the SEEA, and incorporate these into national policy analysis and development planning. ${ }^{17}$

\subsubsection{Context}

Twenty years ago Agenda 21 identified the need for a systems approach to monitoring the transition to sustainable development and proposed a specific solution: the development of integrated environmental and economic accounts. Over the past two decades, the international official statistics and accounting communities have responded to this need through a rigorous and global process to develop a System of Environmental-Economic Accounts (SEEA) within the broader set of international statistical standards.

A multi-year process of revision to the System of EnvironmentalEconomic Accounting was initiated by the United Nations Statistical Commission and produced some results in early 2012. The new SEEA, which sets an international standard for environmental accounting, includes three volumes:

17 www.wavespartnership.org/waves/ 
- Volume 1 (published in March 2012): the core environmental resource accounts, which measure in physical terms the energy, water and material flows that cross the boundary between the economy and the environment and circulate within the economy.

- Volume 2 (expected by February 2013): the Ecosystem Capital Accounts, which aim to measure the state of ecosystems and their capacity to provide ecosystem services, besides calculating the costs of avoiding or repairing environmental damages.

- Volume 3 (expected after Volume 2 is completed): extensions and applications of the accounts, i.e. various monitoring and analytical approaches that could be adopted using SEEA data in order to be used to inform policy analyses.

The approach that is the focus here is the SEEA Volume 1, which is known as the Central Framework of the SEEA.

The WAVES initiative was launched by the World Bank at the CBD meeting in October 2010. WAVES is a 5-year global program to implement natural capital accounting (establish environmental accounts based on the SEEA) in a critical mass of countries, both developed and developing - including ecosystems - to:

- Demonstrate policy usefulness.

- Develop agreed methods for ecosystem accounting (SEEA Volume 2).

Currently, implementing partners include countries such as Botswana, Madagascar, Colombia, Costa Rica and the Philippines.

At Rio+20, WAVES called for countries beyond WAVES partners to:

- Implement environmental accounting where there are internationally agreed statistical standards - the System of Environmental and Economic Accounting (SEEA) for material natural resources such as energy, forests.

- Develop methodology for the more difficult to measure natural capital - ecosystem services.

- Demonstrate how environmental accounting can support decisionmaking for sustainable development. 
At Rio+20 there was also a wider commitment to environmental accounting signed by 56 countries, the European Commission and 86 companies. It is expected that this will lead to increased engagement in the WAVES project. ${ }^{18}$ Note for example that the European Commission is understood to be committing to supporting WAVES.

\subsubsection{Governance and process}

As mentioned above, a multi-year process of revision to the System of Environmental-Economic Accounting was initiated by the United Nations Statistical Commission and culminated in the adoption of the SEEA Central Framework as an international statistical standard for official statistics by the Statistical Commission of the United Nations at its 43rd session in 2012.

WAVES is lead by the World Bank but other partners in the partnership include the UNDP, UNEP, UNCEEA, partner countries, NGOs, academics. WAVES ambition is that natural capital accounting be implemented in at least 6-10 countries over the next few years.

In implementing partner countries a structured process is in place to help countries make progress on selected accounts (see figure below). It comprises of a 1-year preparation phase through mid-2012, followed by a 4 year implementation phrase through to $2015 / 2016 .{ }^{19}$

${ }^{18}$ www.wavespartnership.org/waves/building-support-natural-capital-accounting-\%E2\%80\%93-what-canprivate-sector-do

${ }^{19}$ www.wavespartnership.org/waves/sites/waves/files/images/Moving_Beyond_GDP.pdf 
Figure 4. Implementation process

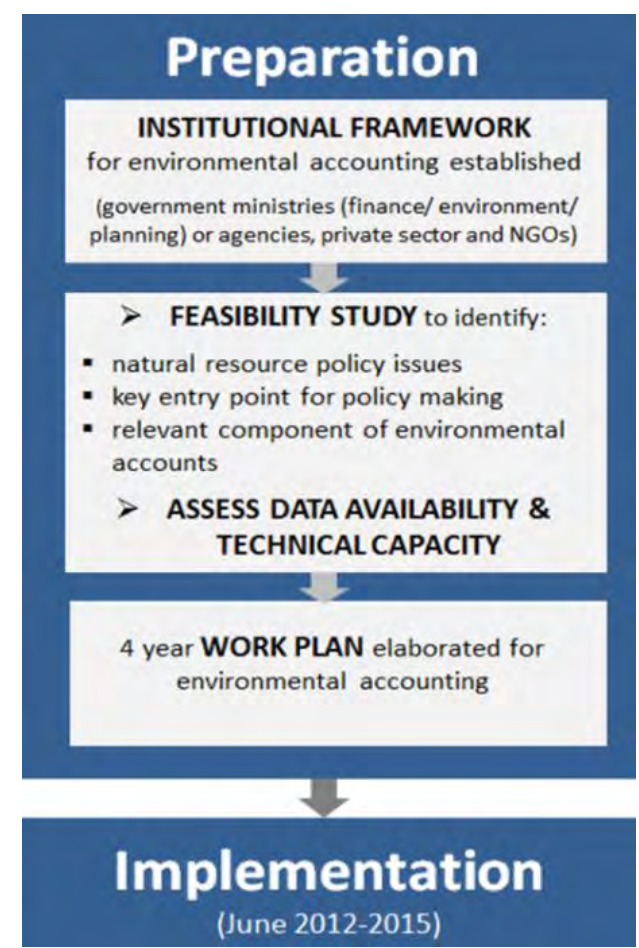

Source: World Bank (2012) Moving Beyond GDP - How to factor natural capital into economic decision-making, URL: www.wavespartnership.org/waves/sites/waves/files/images/ Moving_Beyond_GDP.pdf

\subsubsection{Rationale and ambition (including what policy objectives it is meant to inform)}

The SEEA provides the internationally moderated framework for reversing the isolation of different types of statistics and for providing indicators that directly respond to the demand of integrated policy-making. Indicators related to initiatives such as "beyond GDP,"20 "Green Economy,"21 "Green Growth"22 and "measuring progress of societies"/"better life," 23 all fit under the umbrella of sustainable development. As is highlighted in section 2.1 of

\footnotetext{
20 www.beyond-gdp.eu/

${ }^{21}$ www.unep.org/greeneconomy/

22 www.oecd.org/greengrowth/oecdworkongreengrowth.htm

${ }^{23}$ www.oecd.org/statistics/betterlifeinitiativemeasuringwell-beingandprogress.htm
} 
this report, indicators derived from accounts provide the measures that allow investigating a whole range of questions relating to resource use (e.g. which sector uses which resources), the impacts of resource use, how sustainable are the observed trends, how effective are instruments that have been put in place to curve resource use, etc.

The main rationale behind WAVES is that accounting for natural capital in the context of national accounts can support long-term growth and that more detailed accounts are needed to better manage our economies. As development can be seen as a process of building wealth and managing a portfolio of capital the current focus on GDP, which is merely income, is misleading. A country can make its income look good when in fact it is just selling its natural capital. Countries assessing their wealth and growth should also look at their natural capital stock.

The WAVES initiative aims to promote sustainable development by ensuring that the national accounts used to measure and plan for economic growth include the value of natural resources. It is dedicated to building capacities in countries to establish environmental accounts based on the SEEA, and incorporate these into national policy analysis and development planning.

WAVES pushes for a critical mass of countries to implement the SEEA central framework and for more work on the development of agreed methodologies where these do not exist presently. The compelling body of evidence of how this can be used for policy-making that is to be gathered through WAVES is meant to help countries decide to invest in such accounts.

\subsubsection{Scope/Focus (issues covered and key outputs)}

The SEEA provides a comprehensive conceptual accounting framework which brings together the blocks representing basic economic, environment and socio-demographic statistics and describes the relationship between them. In addition to economic and socio-demographic statistics, the SEEA relies on basic environment statistics such as statistics on natural resources such as water, energy, forests, flows of materials and pollutants which are usually collected for specific purposes. The SEEA adds value to individual information components by bringing them together to inform integrated policies, evaluate trade-offs between different policies and evaluate their impacts across domains of the economy, the environment and society. The specific accounts included in the SEEA Central Framwork cover: physical flow accounts (SEEA Vol.1, chapter 3), 
environmental activity accounts and related flows (SEEA Vol.1, chapter 4), and asset accounts (SEEA Vol.1., chapter 5).

As regards the scope of the SEEA, it is important to highlight that only environmental assets with potential economic value and going through a production process are included in the accounts.

In the context of WAVES, the integration of natural capital into national accounts happens through the framework of the integrated economicenvironmental accounts (SEEA), and in particular its central framework (Volume 1). WAVES's perspective is that while monetary data adds an additional dimension, physical stock and flow indicators are already very useful. WAVES calls for countries to implement the SEEA where there are already agreed methodologies and join in developing methodologies for including natural capital which currently can't be included and also ecosystem services (SEEA Volume 2). ${ }^{24}$ This then lays the basis for producing indicators for monitoring performance at the national level and for sector-specific analysis leading to a more optimised use of natural assets.

Figure 5: SEEA: Vol1, Vol2 and relation to SNA

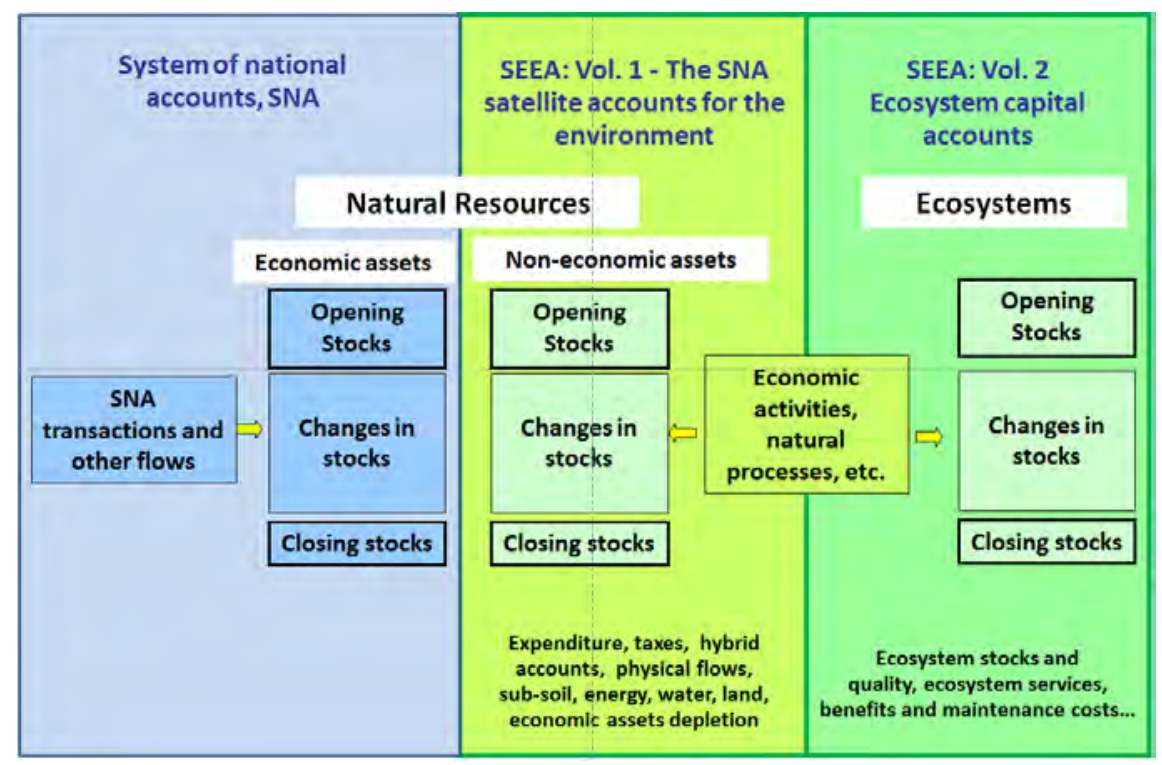

Source: Adapted from RM HASSAN - UN The System of Environmental and Economic Accounting (UN 2003). RANESA Workshop June 12-16, 2005 Maputo and Jean-Louiis Weber (2011).

${ }^{24}$ www.wavespartnership.org/waves/sites/waves/files/images/Moving_Beyond_GDP.pdf 
In the context of the WAVES initiative, the understanding is that environmental accounts can be implemented incrementally: a country can initially focus on the environmental resources that are most useful for national policy.

\subsubsection{Strengths / Opportunities}

WAVES is heavily focused on promoting the implementation of the SEEA Central Framework (SEEA Volume 1). The strength of the SEEA central framework is that it contains the internationally agreed standard concepts, definitions, classifications, accounting rules and tables for producing internationally comparable statistics on the environment and its relationship with the economy. This makes it an excellent starting point for the development of environmental economic accounts and is an essential basis for producing indicators for monitoring performance at the national level and for sector specific analysis leading to a more optimised use of natural assets. ${ }^{25}$

The environmental accounts as included in the SEEA Central Framework can be implemented incrementally, which means that a country can initially focus on the environmental resources that are most useful for national policy.

In addition to encouraging the implementation of the SEEA Central Framework (SEEA Volume 1), the WAVES initiative also encourages and supports countries that are willing to work on the development of new methodologies where these do not exists, in particular ecosystem services.

Particularly interesting elements of the SEEA implementation include:

- The implementation of the SEEA can allow for an integration of natural capital wealth within the assessment of economic performance.

- The flexibility of the SEEA accounting framework makes it equally applicable for data rich and data poor environments.

- The modular aspect of the SEEA allows for multiple purposes and multiple scales of analysis; it can be aligned with the particular policy context of a given country.

${ }^{25} \mathrm{http} / /$ unstats.un.org/unsd/envaccounting/White_cover.pdf 
In short, the strong ties between the WAVES and the United Nations Statistical Commission's SEEA - which ensures due links with the existing System of National accounts - is what makes its strength. The opportunities this provides to analyse the sources of pressures on ecosystems and biodiversity and their evolution over time are key to the monitoring of pressures on the environment and progress towards reducing in particular those that are harmful to biodiversity.

\subsubsection{Current weaknesses / Limitations}

As a primarily World Bank led initiative, the thinking behind WAVES is strongly geared towards natural resources as a component of a country's national wealth (for low income countries, natural capital makes up a significant share of total wealth, $36 \%$ on average) and is unlikely to attempt a very differentiated approach (from a biodiversity perspective) in the area of ecosystem accounting.

As regards the integration of the value of biodiversity and ecosystems into national accounting more specifically, it must be stressed that the SEEA Central Framework is quite limited in that it may primarily provide information on one type of ecosystem service, i.e provisioning services. Similarly, the central framework does at this stage not provide accounts for the stock in different ecosystems nor accounts for the flows of services from specific ecosystems (which could give insights into their state).

Thus, the SEEA Central Framework does not allow analysing the state (quality) of ecosystems or capturing the extent to which they are degraded or deteriorating. A country engaging in the WAVES would have to be prepared to be proactive in experimenting with the development of ecosystem accounts that provide this type of information and to invest quite some resources in their development, though of course this would benefit the wider development of SEEA Vol 2. At the same time, it could benefit from the experiences gained both though other WAVES countries working on experimental ecosystem accounts and disseminated across the partnership. 


\subsection{EEA's simplified Ecosystem Capital Accounts (ECA)}

\subsubsection{Summary}

Since 2009 the European Environment Agency (EEA) has been developing the simplified Ecosystem Capital Accounts (ECA) to develop a tool to help improve the understanding of changes in the natural capital. It also aims to help support the development of a series of key indicators to improve the evidence base for decision making.

The methodological framework was published in $2011 .{ }^{26} \mathrm{~A}$ fast track assessment is currently nearing completion, with a view of reporting on the first natural capital accounts in early 2013. The ECA is meant as the European contribution to the Volume 2 of the SEEA revision.

ECA does not aim to generate new data, as its function is to collect existing statistics (e.g. remote sensing data, land cover data, statistics at different regional level) in order to favour their use and interlinkages. As statistics are generated with different detail, models are used to refer all data to a 1 square kilometre grid.

\subsubsection{Context}

The ECA needs to be seen as one of the European contributions to the development of methodologies to further develop SEEA Volume 2 which focuses on the development of accounts that would help measure the state of ecosystems and their capacity to provide ecosystem services and calculating the costs of avoiding or repairing environmental damages.

\subsubsection{Governance and process}

The EEA has been engaged in the SEEA revision and associated processes (London Group, UNCEEA, International Experts Group on Environmental Accounts, TEEB) over a number of years and has taken the initiative to develop a European contribution to the SEEA Volume 2. It is carrying out this work in conjunction with Eurostat, a range of EEA topic centres, JRC and wider collaborations. To obtain peer review comments and help develop a robust approach and results, the EEA presents the

${ }^{26}$ EEA (2009) An experimental framework for ecosystem capital accounting in Europe", EEA technical report No.13/2011, http://www.eea.europa.eu/publications/an-experimental-framework-for-ecosystem 
work in various fora, including the regularly held international Experts Meetings on Environmental Accounts. ${ }^{27}$

\subsubsection{Rationale and ambition (including what policy objectives it is meant to inform)}

Overall ambition: to contribute to the Vol. 2 SEEA revision by both developing a conceptual framework and applying it at the European scale to test and demonstrate the approach and highlight issues of relevance. ECA will not generate new data, but its role will be to collect existing statistics and refer them all to a square km grid. The objective is to make data easily available to policy makers and researchers through a userfriendly interface, which will be available in the EEA webpage. In this way, it will facilitate cross-cutting analyses along different environmental policy areas (e.g. water policies, carbon policies, land policies). In addition, it will offer an approach that can inform policies aimed to meeting the Strategic Plan for Biodiversity 2011-2020 Target 2. The current fast track is focusing on the natural capital accounts expressed in physical terms. The work on the value of nature expressed in monetary terms is for a later exercise.

Content: ECA's overall objective is to provide information on a) the accessible ecosystem resources (i.e. the share of the available resources that can be used without degrading the environment); b) the intensity of use of this accessible resource; c) the change in the capability of ecosystems to deliver their services over time.

ECA is itself currently an experimental account and the first track implementation (which will be ready in 2013) is expected to be a step forward in meeting part of the above objectives. However, these objectives are very ambitious, and meeting them will require a significative effort over the next years. Among the most challenging objectives, future ECA aims to include monetary values (based on restoration costs) and the flows of ecosystem services.

\footnotetext{
${ }^{27}$ For papers see http://unstats.un.org/unsd/envaccounting/seeaLES/egm/lod.htm for the December 2011 meeting in London and http://unstats.un.org/unsd/envaccounting/seeaLES/egm2/lod.htm for the May 2012 meeting in Melbourne.
} 


\subsubsection{Scope/Focus (issues covered and key outputs)}

The ECA system covers all ecosystem categories, including forests, wetlands, agricultural land, cities and the sea. Accounts are currently being developed for: 1) Land cover; 2) Biomass/carbon; and 3) Water. A future version will also possibly include Landscape and rivers integrity accounts and biodiversity accounts (see also Annex 1).

The current fast track experimental ECA is focusing particularly on the natural capital stocks in the areas of water, land and biomass carbon accounts. The physical flow of ecosystem services and the monetary values of the changes in stocks and the flow of services are not currently the focus of the analysis and will not feature in the 2012 experimental ECA. See Figure 1 in the annex.

The original long-term ambition was to be able to identify the "optimal" level of ecosystem services or calculating them on the basis of the need to recover from historical damages, thus potentially allowing calculating the distance from such optimal /targeting level. In addition, it was thought, one could try to estimate the sustainable ecosystem capability, i.e. the amount of flows and stocks accessible without degrading the environment. A loss of ecosystem capability could have provided an indication of environmental degradation. ${ }^{28}$ While these have been stated as long-term ambitions, one should not expect them to be realised in a near future.

\subsubsection{Strengths / Opportunities}

ECA is a very ambitious approach, as it aims not only to assess the stocks and flows of natural resources, but also to measure them against local availability, thereby giving an indication of the environmental degradation at the local scale. In addition, while the environmental accounting contained in SEEA Volume 1 only includes the flows of natural resources between the environment and the economy, ECA aims at taking into account also the ecosystem services that do not directly enter the economy (e.g. life support functions and non-market public goods, such as water purification/quality, carbon storage in natural assets, cultural amenities), and therefore tend to receive less focus by policy makers. For this reason, ECA will provide a wider picture of the benefits that

${ }^{28}$ EEA (2009) An experimental framework for ecosystem capital accounting in Europe", EEA technical report No.13/2011, http://www.eea.europa.eu/publications/an-experimental-framework-for-ecosystem 
nature delivers to the human society, and in this way it will contribute to a better management of the environmental resources.

\subsubsection{Current weaknesses / Limitations}

The other side of the coin of ECA's ambitious approach is the huge methodological challenges that it implies. In fact, trying to take into account the ecosystem services that do not directly enter the market imply the need for many assumptions and a significant effort in data collection. In addition, the conversion of all indicators in one unit of measurement, notably the ECU, and their aggregation in one only indicator inevitably implies a loss of information, as negative changes in one dimension (e.g. carbon storage in biomass) can be offset by positive changes in another dimension (e.g. water availability). The ongoing fast track assessment is already helping to clarify the data challenges. Other strengths and weaknesses will become clear in the coming months as the first results of the fast track analysis are analysed and reported on.

\subsection{UK National Ecosystem Assessments (NEA)}

\subsubsection{Summary}

The UK National Ecosystem Assessment (UK NEA), published in 2011, was the first comprehensive analysis of the UK's natural environment in terms of the benefits it provides to society and continuing economic prosperity. It was an inclusive process involving many governments, academic, NGO and private sector institutions. ${ }^{29}$

\subsubsection{Context}

The need for the UK NEA arose from findings of the 2005 global Millennium Ecosystem Assessment (MA), which not only demonstrated the importance of ecosystem services to human well-being, but also showed that at global scales, many key services are being degraded and lost. As a result, in 2007 the House of Commons Environmental Audit recommended that the Government should conduct a full MA-type assessment

${ }^{29}$ http://uknea.unep-wcmc.org/ 
for the UK to enable the identification and development of effective policy responses to ecosystem service degradation.

The UK NEA commenced in mid-2009 and reported in June 2011, as a part of the Living With Environmental Change (LWEC) initiative.

Parallel to the UK NEA an economic analysis ${ }^{30}$ was developed which addressed the following questions: How do ecosystem services affect human well-being, who and where are the beneficiaries, and how does this affect how they are valued and managed? What are the economic implications of different plausible futures? Using spatially sensitive value functions from pan UK spatially referenced data, applied in six scenarios, values were estimated.

\subsubsection{Governance and process}

The UK NEA first phase was an independent study funded by Defra, the Scottish Government, the Welsh Assembly Government, the Northern Ireland Executive, the Natural Environment Research Council and the Economic and Social Research Council. The funding was brought together through the Living with Environmental Change Partnership, formed of 22 Government departments, devolved administrations, research councils and other bodies.

The UK NEA was an inclusive process; many government, academic, NGO and private sector institutions helped to design the assessment, contribute information and analyses, review the preliminary findings, and promote the results.

The scientific analysis was led by two Co-Chairs, the design and assessment process was led by an Expert Panel, consisting of 27 of the UK's leading natural scientists, economists and social scientists, a user group, with representatives from government agencies, NGOs and the private sector across the UK, informed the approach and outputs to ensure relevance for different audiences, a team of co-ordinating Lead Authors supervised teams of authors writing the chapters for the assessment, a client group, consisting of the organisations that commissioned the UK NEA, ${ }^{31}$ provided guidance and oversight and an independent secretariat ${ }^{32}$ co-ordinated the different assessment activities.

\footnotetext{
30 Bateman et al., 2011.

31 Defra (England), the devolved administrations of Northern Ireland, Scotland and Wales, together with some of the research councils (Natural Environment Research Council and Economic and Social Research Council).

32 United Nations Environment Programme World Conservation Monitoring Centre (UNEP-WCMC).
} 
The UK NEA follow-on project continues to be an inclusive process by retaining a governance structure similar to the first phase and comprising of an Expert Panel and its Co-Chairs, a Stakeholder Group, Principal Investigators leading their research teams, a Funders Group and a Secretariat.

The (ongoing) follow-on phase is being funded by the Department for Environment, Food and Rural Affairs (Defra), The Welsh Government and three research councils: the Natural Environment Research Council (NERC), the Economic \& Social Research Council (ESRC) and the Arts \& Humanities Research Council (AHRC), and coordinate with and leverage numerous ongoing research activities throughout the UK.

\subsubsection{Rationale and ambition (including what policy objectives it is meant to inform)}

The UK NEA is meant to help decision-makers make better decisions that impact on the UK's ecosystems to ensure the long-term sustainable delivery of ecosystem services for the benefit of current and future populations in the UK, thereby addressing the needs set out in Defra's current Action Plan for Embedding an Ecosystems Approach (Defra, 2007).

The UK NEA was also meant to support global and regional obligations such as the Convention on Biological Diversity's call on countries to conduct such assessments and the European Union Water Framework Directive, which encourages the management of ecosystem services.

The UK NEA had three objectives:

- To produce an independent and peer-reviewed UK National Ecosystem Assessment for the whole of the UK.

- To raise awareness of the importance of the natural environment to human well-being and economic prosperity.

- To ensure full stakeholder participation and encourage different stakeholders and communities to interact and, in particular, to foster better inter-disciplinary cooperation between natural and social scientists, as well as economists.

\subsubsection{Scope/Focus (issues covered and key outputs)}

The UK National Ecosystem Assessment (UK NEA) evaluated the UK natural environment in terms of the benefits it provides to society and the nation's continuing prosperity. It found that $30 \%$ of the services provided by the natural environment were in decline. The innovative assessment set the foundation for many of the actions proposed within a 
Natural Environment White Paper in which the government laid out actions to mainstream the value of nature across society. ${ }^{33}$ As part of efforts to "grow a green economy" the report indicates that natural capital will be fully included in the UK Environmental Accounts. It also announced the creation of the Natural Capital Committee ${ }^{34}$ to advise the government on integrating the value of natural capital into their national accounts. It indicates that the value of natural capital needs to be taken into account as part of economic planning, by comparing the costs and benefits of different actions, and prioritizing natural capital investment based on those that will provide the best returns. It also indicates that environmental taxes and other market-based instruments might be used to deliver better environmental and economic outcomes. 35

The UK NEA, through its reports, website and key messages has built on previous studies by:

- Creating a compelling and easily understood explanation of the state and value of the UK's natural environment and ecosystem services.

- Providing a unique synthesis of what is currently known, by collating existing information on ecosystems and ecosystem services and exploring the interlinkages between habitats, ecosystem services and biodiversity.

- Placing ecosystem services in the spotlight and focusing attention on how our natural ecosystems support their provision.

- Identifying knowledge gaps for habitats and ecosystem services that will inform future research.

- Assisting in further embedding the concepts of ecosystem services and the ecosystem approach and strengthening decision-making at all scales from landowners to local government and companies to national administrations.

In 2011 the UK National Ecosystem Assessment (UK NEA) delivered a wealth of information on the state, value (economic and social) and possible future of terrestrial, freshwater and marine ecosystems across the UK, but also identified a number of key uncertainties. Therefore, the Government is committed to adding to this knowledge base and is there-

\footnotetext{
${ }^{33}$ HM Government, (2011) The Natural Choice: securing the value of nature, URL: http://www.officialdocuments.gov.uk/document/cm80/8082/8082.pdf

${ }^{34}$ UK Natural Capital Committee: www.defra.gov.uk/naturalcapitalcommittee/

$35 \mathrm{http}$ ///unstats.un.org/unsd/envaccounting/seeaLES/egm2/PolicyOP.pdf
} 
fore supporting a two-year long follow-on phase of the UK NEA. The follow-on phase will further develop and promote the arguments that the UK NEA put forward and make them applicable to decision and policy making at a range of spatial scales across the UK to a wide range of stakeholders.

More specifically, this second phase will focus on the following four areas: ${ }^{36}$

A. The further development of the economic analysis of the UK NEA to increase the breadth of ecosystem services analysed, to broaden our understanding of the value of natural capital stocks and ways in which this value can be better represented in national wealth accounts, as well as analyse the macroeconomic implications of the findings of the UK NEA.

B. Further exploration of cultural ecosystem services and how cultural, shared and plural values for ecosystem services can be better understood and operationalised into a range of decision making contexts alongside economic analyses.

C. Development of the analysis of future ecosystem changes, applying and developing the UK NEA scenarios to enable and enhance the outputs of the other objectives and to examine a range of societal responses to the possible future changes.

D. The development and enhancement of tools and other supporting materials for use by a range of key user groups from the public, private and voluntary sectors, to enable them to make best use of this evidence. The balance in emphasis between developing totally new tools or enhancing existing assessment processes will depend upon an initial review of user needs.

\subsubsection{Strengths / Opportunities}

The focus of the UK NEA is on ecosystems, the benefits they deliver to the economy and their state (see Figure 6). It has proved effective in providing evidence of the value of nature to the economy as a whole, as well as providing values for a range of ecosystem services (substantially drawing on existing assessments and studies).

${ }^{36}$ http://uknea.unep-wcmc.org/LinkClick.aspx?fileticket=CTjLf8V9E64\%3d\&tabid=129 
Figure 6: Relative importance of Broad Habitats in delivering ecosystem services and overall direction of change in service flow since 1990

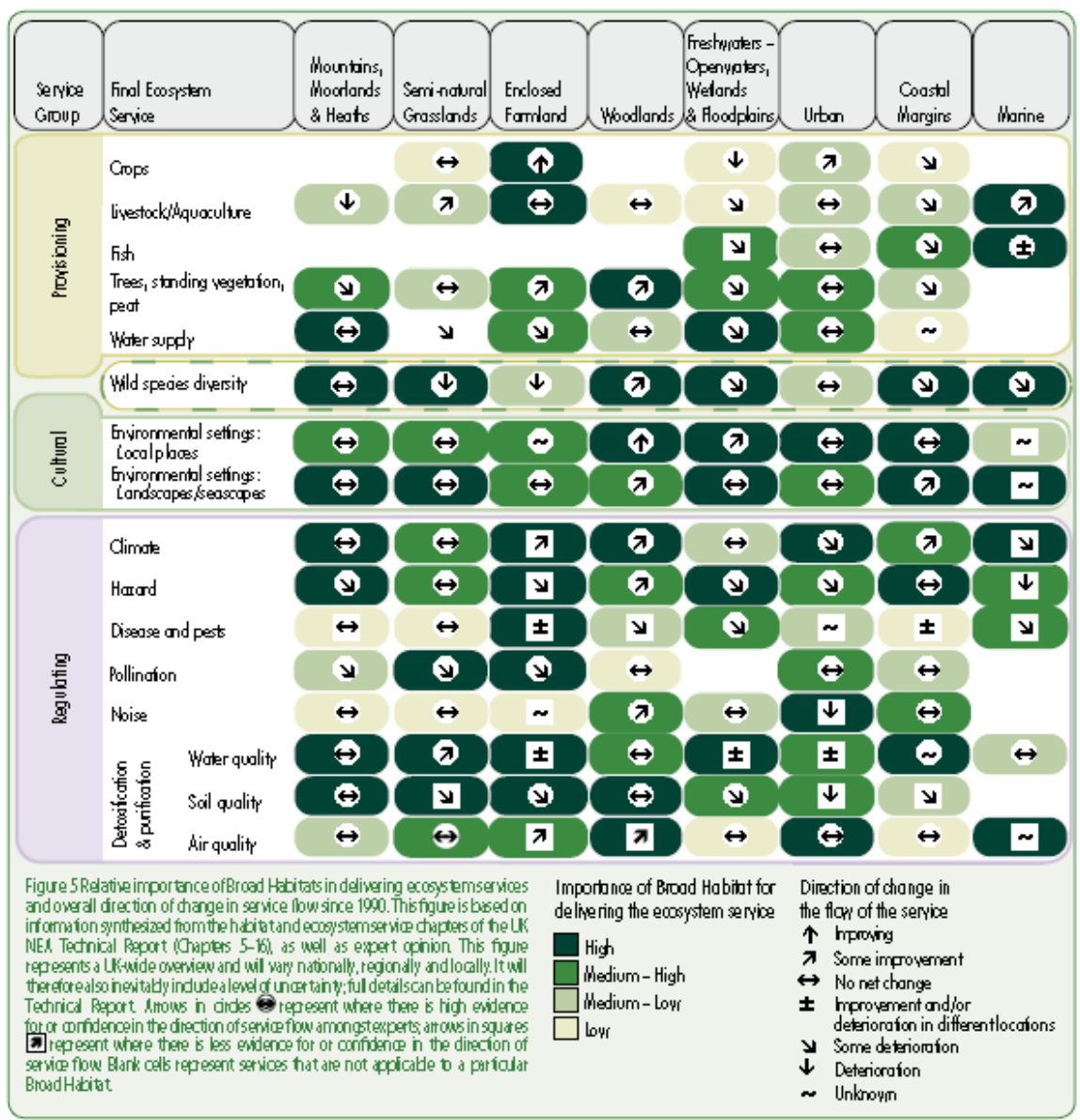

Source: UK National Ecosystem Assessment, 2011 Executive Summary.

It has provided a clear methodology and approach that advances the work in the field. It builds on the MA 2005 ecosystem service classification, adapting it for the ambitions of valuation (see Figure 7). It also combines rich data and practical valuation in a spatial context, building on mapping, making the results more practically relevant to regional decision making (see Figure 8). 
Figure 7: The full set of ecosystem processes, services, good/benefits and values used in the UK NEA

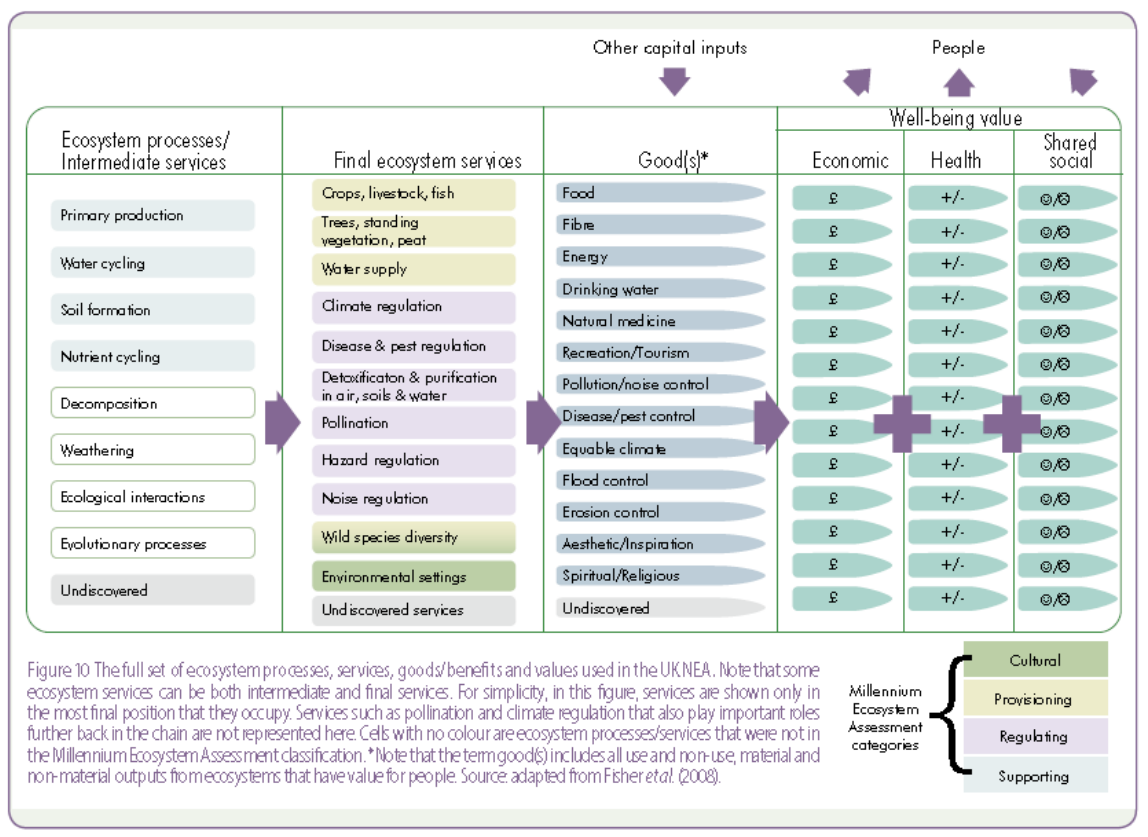

Source: UK National Ecosystem Assessment, 2011 Executive Summary.

It has also created an important information foundation and network of organisations and experts to build on. This should facilitate improved governance and decision making by improving the evidence base - in principle for agriculture, forestry, fisheries and water policies, as well as for health policies, regional policy, and coastal zone management.

In the current phase, some of the work packages are particularly focused on the development of a framework for undertaking an "asset check" to fill some gaps remaining after the previous phase.

The information produced in the first phase has however not been produced in view of an integration into the national accounting system and is therefore not structured around accounts that comply with high statistical standards and easily linked to the system of national accounts. If the incorporation of biodiversity and ecosystem values into national accounts remains a key ambition, there probably are more focused ways in which such data can be produced. The NEA second phase is exploring how to facilitate the links. 
Figure 8: Economic values that would arise from a change of land use from farming to multi-purpose woodland in Wales (E per year)

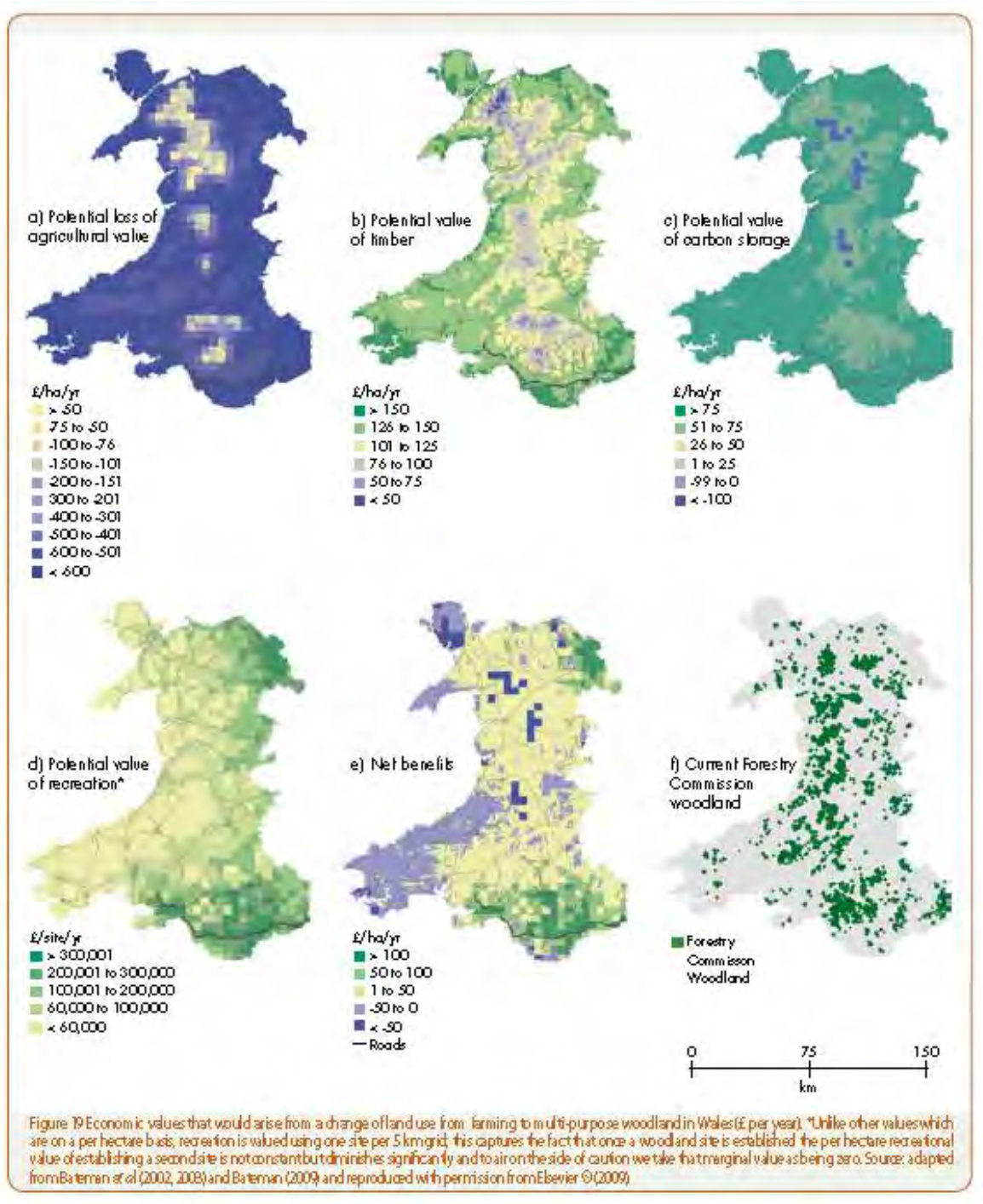

Source: UK National Ecosystem Assessment, 2011 Executive Summary.

\subsubsection{Current weaknesses / Limitations}

The UK NEA is, by design, very broad in scope and in many areas it goes beyond what is needed to meet the one specific objective of integrating the values of biodiversity in national accounting (as the objectives were wider than a pure focus on contributing to accounts). It is also very resource intensive exercise. It seems to have relied heavily on in-kind con- 
tributions by a large range of actors, which cannot be automatically assumed to work in a different context/country.

The "ecosystem assessment" part of the NEA is understood to have already been experimented in some of the Nordic countries ${ }^{37}$ and there might be some overlap with past and/or ongoing research efforts if the process/approach were copied 1:1. If something similar to the UK NEA were attempted in (some of) the Nordic countries, care should be taken to build on past and/or link it to ongoing efforts and consideration might need to be given to restricting somewhat the scope of the assessment for it to focus on the specific needs and priorities of the Nordic countries (which might not necessarily be the same as the one behind the design of the UK NEA, which might also have been influenced by institutional contexts).

\subsection{Canada's Measuring Ecosystem Goods and Services (MEGS)}

\subsubsection{Summary}

Measuring Ecosystem Goods and Services (MEGS) ${ }^{38}$ is a Canadian interdepartmental project to develop statistical infrastructure to support the valuation of ecosystem goods and services and create pilot ecosystem accounts. Through the MEGS project, Statistics Canada and partner organisations are building the statistical infrastructure for a System of Ecological Accounts, including developing spatial infrastructure, integrating biophysical data and developing a consistent approach to valuation.

\subsubsection{Context}

Demand for this project included the 2010 recommendation by the Deputy Ministers' policy committee on Climate Change, Energy and Environment to adapt Statistics Canada's environment and resource accounts by incorporating data on biodiversity and ecosystem goods and

\footnotetext{
37 Norway pioneered the ecosystem services framework by participating in the Millennium Ecosystem Assessment published in 2005 by carrying out a pilot study in 2001 investigating the possibility of an assessment of ecosystem services at a regional scale. The results of the 2002 assessment might provide some useful inputs for the future development of ESS indicators.

${ }^{38} \mathrm{http} / / /$ unstats.un.org/unsd/envaccounting/londongroup/meeting18/LG18_p11_MEGS\%20Building\%20Ex perimental\%20Ecosystem $\% 20$ Accounts.pdf
} 
services. Further consideration has since been given to the priorities of partner organizations, for example reporting requirements through the Federal Sustainable Development Strategy. ${ }^{39}$

There is demand from various departments for monetary values of ecosystems and their services to support discussions of protection, conservation, climate change, sustainability, pollution prevention, land use change. In addition the MEGS is seen as an opportunity to raise argument beyond "environment" versus "economy" to understand the real contribution of ecosystems to human well being, sustainability and "green growth".

The development of valuation models and frameworks for the social and economic analysis of policy decisions having environmental impacts is seen as a key component for the integration of environmental, economic and social priorities into policies and programs. To that effect, Environment Canada (EC) has been developing an Ecosystem Goods and Services (EG\&S) Analytical Framework that allows the integration called for by the Federal Sustainable Development Strategy. The application of the framework is meant to include valuation of EG\&S, including wildlife habitat, water purification, carbon sequestration etc. to make decisions related to protected areas, species at risk and other issues.

MEGS is a 2 year Statistics Canada-led interdepartmental initiative aiming to develop prototype ecosystem accounts to support policy needs of:
A. Environment Canada
B. Agriculture and Agrifood Canada
C. Fisheries and Oceans Canada
D. Natural Resources Canada
E. Parks Canada

The humans resources allocated to MEGS represent a "virtual" team of 60 mostly part-time staff in 6 departments.

${ }^{39} \mathrm{http}$ //unstats.un.org/unsd/envaccounting/seeaLES/egm2/PolicyOP.pdf 


\subsubsection{Governance and process}

The work on the MEGS is led by the Statistics Canada, which has played an active role in developing environmental statistics over the years. The choice of the statistical agency was considered justified for the following reasons:

- Existing expertise in natural resource valuation.

- Spatial infrastructure with links to socio-economic information (e.g., settlements).

- Links to System of National Accounts (including input output tables) to understand the economic value of ecosystem services.

- Expertise with standards and classifications.

- North American Industry Classification System (NAICS), Standard Classification of Goods (SGC), North American Product Classification System (NAPCS), National Occupation Classification(NOC). ${ }^{40}$

- Statistics Canada has internal standard for drainage areas.

- Adherence to statistical quality standards (e.g., fitness for use; trends).

- Impartial and long-term perspective.

Furthermore, Statistics Canada has worked on producing ecosystem accounts for the past 15 years. They have worked mostly on resources, such as water, subsoil assets, timber, as well as energy related accounts (including energy use). Statistics Canada has also developed land accounts in which they monitor space and land cover. Most of the developed accounts are expressed in physical terms and only a few are both in physical and monetary terms. All of the above are tied back to the national accounts (although water to a lesser extent). There are three categories (resources, land, ecosystems) in the natural capital model.

Other departments including Industry Canada, Finance Canada and Human Resources and Skills Development Canada were involved in the initial project design and are considered potential users. Other potential data users include provincial, regional and local decision-makers. For example, valuation data might be used to facilitate performance reporting, environmental assessment and trade-off decisions in land use planning. There are working groups on specific issues including coastal and

40 NAICS: North American Industry Classification System; SGC: Standard Classification of Goods, NAPCS; NOC. 
marine ecosystems, valuation, wetlands, special data, and dissemination. All groups work together to try to produce a number of case studies that would represent experimental ecosystem accounts.

\subsubsection{Rationale and ambition (including what policy objectives it is meant to inform)}

Project goals include providing high quality data to policy makers and the public that allow for the exploration of questions relating to the impacts of growth on the natural capital base and implications for sustainability, as well as the most effective use of natural capital in support of human well-being.

In a nutshell the objectives are to:

1. Assemble available data and integrate it so that it can be used to produce accounts (as statistical infrastructure).

2. Create experimental accounts to measure extent and quality of ecosystems.

3. Develop further their understanding of valuation techniques.

The reasons why ecosystem accounts are thought to be needed are that it would help:

- Coherent framework for spatial and biophysical data.

- Ensure interoperability of information.

- Coherence of indicators.

- Consistent and defensible means of including value of ecosystem services in economic decisions.

- Enhance credibility of ecosystem valuation.

- Ensure values are non-zero.

- Coordination of multidisciplinary work on ecosystems (spatial, biophysical, economic...).

The MEGS vision of ecosystem accounts includes data on the stock of ecosystems and flows of ecosystem goods and services, using physical, monetary and qualitative measures, classified by standard ecosystems groupings (e.g. wetlands, lakes/rivers, forests, rangeland etc.) For example, physical stock information would include information on the extent or size of ecosystems, but also requires consideration of qualitative dimensions, while physical and monetary flows measure the quantity and value of ecosystem goods and services provided by the ecosystem. 


\section{MEGS vision of ecosystem accounts ${ }^{41}$}

Spatially-referenced land/water cover data

- Various times in past and as close to present as possible

- As detailed as possible (30m-250m)

- Include terrestrial, freshwater, coasts, wetlands and marine ecosystems

- Classified according to a common standard for ecosystems

Coherent biophysical data to assess ecosystem quality linked to services

- Such as air quality, water quality, species diversity, ecosystem productivity, land cover, climate maintenance, pollination, water management, etc.

Methodology and standards for assigning monetary values to ecosystems

- Value what can be valued; measure changes in quality for rest

\subsubsection{Scope/Focus (issues covered and key outputs)}

The focus of the initiative is on:

- Building a statistical infrastructure

- Develop coherent spatial frameworks and georeferenced data

- Adopt common classifications

- Measuring extent and quality of ecosystems

- Acquire and integrate data

- Measuring indicators

- Refining approaches to valuation

- Produce exploratory case studies

${ }^{41}$ http://www.cirano.qc.ca/icirano/public/pdf/Ecosystems_Statistics_Canada.pdf 


\subsubsection{Strengths / Opportunities}

Ecosystem accounts appear to be quite a central element of the MEGS. The involvement of different government departments in the design and funding of the programme suggests that the outputs will be policyoriented and respond to the demand of policy-makers involved in the management of natural resources. The foreseen application of the framework (valuation of EG\&S, including wildlife habitat, water purification, carbon sequestration etc.) suggests that at least some of the accounts that will be developed through the MEGS will be relevant in the context of the implementation of the biodiversity Strategy, especially since it is expected that the output of the MEGS may help take decisions related to protected areas, species at risk and other issues. The choice of statistics Canada as the lead organisation means that relevant experiences and approaches, such as those gathered through the development of the SEEA central framework, are taken into account where relevant and that opportunities to create links with the SNA, in view of an integration of biodiversity values into national accounts, should not be missed. One other aspect which suggest the work of statistics Canada could be of interest to the Nordics is that the areas that are likely to be the focus in the accounts development could be somewhat similar to those that are of interest in the Nordic context given somewhat similar geographic conditions and endowment in natural resources.

\subsubsection{Current weaknesses / Limitations}

There may be some limitation in the prototype accounts that are under development when it comes to using them for the development of indicators to support the pursuit and monitoring progress towards biodiversity-related policy objectives. Given the accounts are to be developed not only for Environment Canada but also for Agriculture and Agrifood Canada, Fisheries and Oceans Canada and Natural Resources Canada, there may be a heavy focus on the stock of natural resources and associated ecosystem services (possibly with a heavy focus on provisioning services). An investigation of the extent to which "softer" ecosystem services such as cultural and, regulating services can and will be factored into the accounts would be worthwhile. It will be important to understand to which extent the approach is suited for capturing the diversity of values associated with biodiversity and ecosystems. 


\subsection{Natural Capital Project - InVEST}

\subsubsection{Summary}

The natural capital project promotes the use of InVEST, a family of tools to map and value the goods and services from nature, thus helping manage natural resources and evaluate trade-offs among these uses and help enhance the cost-effectiveness of investments into biodiversity and human well-being. These tools can be used by all actors managing natural resources, whether they are governments, non-profits or corporations. 42

\subsubsection{Context}

Natural Capital Project is led by an interdisciplinary team of core scientists and project leaders from Stanford University, The Nature Conservancy, World Wildlife Fund, and the University of Minnesota. ${ }^{43}$

\subsubsection{Governance and process}

The Natural Capital Project is a partnership among Universities and NGOs that works to develop and provide practical ecosystem services concepts and tools, apply these tools in select areas around the world, and engage influential leaders to advance change in policy and practice through mainstreaming the approaches. In addition to working with their core partners, they collaborate with many governments, corporations, universities, and other non-profit organizations to integrate ecosystem services approaches into major natural resource decisions, and improve the state of biodiversity and human well-being by motivating cost-effective investments in both.

Thus, the developers of the tools linked to InVEST claim that it can equally be used by governments, non-profits, and corporations that manage natural resources for multiple uses and must evaluate trade-offs among these uses.

42 www.naturalcapitalproject.org/

${ }^{43}$ www.naturalcapitalproject.org/people.html 


\subsubsection{Rationale and ambition (including what policy objectives it is meant to inform)}

The starting point of the developers of the tool is the acknowledgement that despite the flow of services that are vital to humanity that ecosystem yield natural capital is poorly understood, scarcely monitored, and, in many cases, undergoing rapid degradation and depletion.

InVEST is meant to ensure natural capital is properly managed by helping fill this gap and enable decision-makers to assess the trade-offs associated with alternative choices and to identify areas where investment in natural capital can enhance human development and conservation in terrestrial, freshwater, and marine ecosystems. ${ }^{44}$

\subsubsection{Scope/Focus (issues covered and key outputs)}

The Natural Capital Project and more specifically its main output, the InVEST tool, does not allow for macro-economic analysis and is not meant to result in environmental information that can be linked with the national accounting framework. This is not to say that the sole scale at which the tool can be applied is only local however. According to the tool's developers it can equally be used at regional and global scales - the spatial resolution of analyses is therefore flexible, allowing users to address questions at scales ranging from the local to the global. Examples of the specific questions it may help answer are provided in the box below.

Questions InVEST can answer:

- How will a new coastal management plan impact seafood harvest, renewable energy production, and protection from storms?

- Conservation organizations can use InVest to align their missions to protect biodiversity with activities that improve human livelihoods.

- Where would reforestation or protection achieve the greatest downstream water quality benefits?

- Corporations, such as bottling plants, timber companies, and water utilities, can use InVEST to decide how and where to make investments to protect their supply chains.

- Which parts of a watershed provide the greatest carbon sequestration, biodiversity, and tourism values?

${ }^{44}$ www.naturalcapitalproject.org/about.html 
- Government agencies can use InVEST to help determine how to manage lands and waters to provide an optimal mix of benefits to people or to help design permitting and mitigation programs that sustain nature's benefits to society.

According to its developers, InVEST is most effectively used within a decision-making process that starts with stakeholder consultations.

Through discussion, questions of interest, management choices, and/or policy options are identified.

Stakeholders develop spatial "scenarios" to show, for example, several alternative areas where fishing might be prohibited, where agricultural land might be converted to residential development, or where climate change is expected to affect precipitation and temperature patterns.

Scenarios typically include maps of potential future land use/land cover and/or marine habitats and ocean uses. These are critical inputs in all InVest models.

Following stakeholder consultations and scenario development, InVEST can estimate how the current location, amount, delivery, and value of relevant services are likely to change in the future.

InVEST models are spatially-explicit, using maps as information sources and producing maps as outputs. InVEST returns results in either biophysical terms (e.g., tons of carbon sequestered) or economic terms (e.g., net present value of the sequestered carbon).

InVEST results can be shared with the stakeholders and decisionmakers who created the scenarios to inform upcoming decisions. Using InVest in an iterative process, these stakeholders may choose to create new scenarios based on the information revealed by the models until suitable solutions are identified.

InVEST models are based on production functions that define how an ecosystem's structure and function affect the flows and values of environmental services. The models account for both service supply (e.g. living habitats as buffers for storm waves) and the location and activities of people who benefit from services (e.g. location of people and infrastructure potentially affected by coastal storms).

Since data are often scarce, the initial versions of InVEST offer relatively simple models with few input requirements. These models are best suited for identifying patterns in the provision and value of environmental services. With validation, these models can also provide useful estimates of the magnitude and value of services provided. 


\subsubsection{Strengths / Opportunities}

The strength of InVEST compared to the other tools is that it is suited to support specific (policy or land-use) decisions relating to resource use at different scales, including the local scale. It is, however, not a tool that would directly support the development of environmental-economic accounts that could be linked to the system of national accounts. As a family of tools to map and value the goods and services from nature it could, however, effectively act as a tool to implement commitments to integration of the values across different policies and in every policydecision having important effects on land and resource (ecosystem) use.

InVEST includes all four ecosystem service categories (provisioning, supporting, cultural and regulating) and biodiversity (species richness). The scale of the output is local and regional. InVEST assessment tools include cultural services, mainly related to recreation and aesthetic and cultural values of landscapes - interesting approach that could provide the necessary framework to combine model outputs and assess impacts on value of ecosystem goods and services. InVEST can therefore usefully be used for regional specific analysis as an additional meta-model for rapid mapping of alternatives and first indications of economic feedback on sectors. InVEST could be useful to bring in the spatial angle, for example by demonstrating links to flooding, as well as developing case studies focusing on ecosystem functions. For sector, ecosystem or policy specific modelling it could be useful to do REDD modelling, use agricultural models, and also carry out modelling of biofuels to address critical questions. In many cases significant work of others can be built on, so care needs to be taken to avoid duplicating existing work.45

It would therefore be worthwhile experimenting its use but it appears unlikely that on its own it would allow to bring about the insights that could be gained from a more tailored process aiming at the development of ecosystem/biodiversity related accounts that can be incorporated in the system of national accounts. That said, the insights gained at the local and regional level could prove to be useful in testing and calibrating national accounts where these are spatially explicit (e.g. ECA). In other words, while not providing data that would directly feed into national accounts, it could sup-

45 IEEP, Alterra, Ecologic, PBL and UNEP-WCMC (2009) Scenarios and models for exploring future trends of biodiversity and ecosystem services changes. Final report to the European Commission, DG Environment on Contract ENV.G.1/ETU/2008/0090r. 
port national accounts by helping to improve data and methods used within the accounts data collection and analysis process.

\subsubsection{Current weaknesses / limitations}

Strictly speaking, InVEST is a decision-making support tool that has not been designed to integrate environmental values into the system of national accounts. It does not offer a stable framework meeting high statistical standards for regular data collection and collation along the lines of standardised reporting by statistical offices. This would however be needed for any ambition for the "incorporation of the values of biodiversity and ecosystems into national accounts" is to have accounts. For this, times series in data allowing to monitor trends over time and to link the data with other accounts (i.e. economic accounts) would be needed. This would help in the analysis of interlinkages across the different types of accounts and filling data gaps that prevent the development of some indicators that integrate the relationship between the economy and ecosystems/biodiversity. Finally, InVEST is a rather data demanding tool (IEEP, 2009). 



\section{Natural capital accounting in the Nordic countries}

This section describes briefly some key policies and activities related to monitoring biodiversity and biodiversity related targets and biodiversity or ecosystems accounting in each Nordic country. The goal of the overview is also to give some insight into the status of the implementation of the CBD targets related to biodiversity and natural capital in the Nordic countries. In addition, the inclusion of values of biodiversity and natural capital in national accounting systems is also of interest. In the context of this study, some needs and criteria for accounting systems of natural capital and biodiversity values are identified for each country.

This section is not intended as a comprehensive review. It's target is mainly to provide some insights on key issues and priorities and to identify some of the needs of the Nordic countries. These serve as input into the analysis of the systems in chapter 4 . The sources of information used are mainly interviews of key stakeholders complemented by publicly available information on key targets and policies.

\subsection{Denmark}

\subsubsection{Key national policies and goals}

The work on the National Strategy and Action Plan (NBSAP) for the Conservation and Sustainable Use of Biodiversity is in progress in Denmark. The revision of the strategy is connected to the governments new "Nature Plan for Denmark", which will be launched in 2013.46

Some of the most important existing policies that address biodiversity are the Policy for Nature protection through the Nature Protection Act, the Natura 2000 programme, the policy on the doubling of the forest area in the next 80 years and the policy on invasive species.

${ }^{46}$ Jesper Tranberg, Ministry of the Environment. 
Denmark has outlined its nature conservation policy objectives in a range of documents:

- The National Strategy for Sustainable Development from 2009 sets targets and principles for sustainable development including the objectives of securing a high degree of biodiversity and preserving Denmark's ecosystems.

- The agreement on Green Growth from 2009 is a political agreement in the Danish parliament. Its purpose is to ensure that a high level of environmental, nature and climate protection goes hand in hand with a competitive and modern agriculture and food industry.

- The overall objective of the National Strategy on Natural Forests (1992-2040) is to conserve the biodiversity of the Danish forests, including the gene resources present in these areas.

- The National Forest Programme from 2002 sets targets for increasing the national forest area and managing the forests in a way that takes the protection of biological diversity better into account.

- The Action Plan for Biodiversity and Nature Conservation (20042009) specifies actions to protect nature and biodiversity in accordance with the National Strategy, EU legislation and the Convention on Biological Diversity.

- The National Action plan on Alien Invasive Species from 2009 gives a number of recommendations on actions to be taken.

\subsubsection{Current biodiversity indicators and accounting}

Statistics Denmark works on environmental-economic accounting, but so far only within the limits of the System of Environmental-Economic Accounts (SEEA) Central Framework (SEEA Volume 1), which does not include ecosystems accounting.

There are 29 indicators related to the 2010 SEBI indicators, ${ }^{47}$ which are in use. A revision of these indicators for the 2020 strategy is expected to be conducted. So far no monetary indicators exist, but an assessment of resources used for biodiversity was reported to CBD in 2012.48

\footnotetext{
${ }^{47}$ Streamlining European Biodiversity Indicators (SEBI).

48 https://www.cbd.int/financial/doc/eu-members-resource-mobilization-en.pdf
} 
Denmark is in the process of starting up a project which aims to address the issue of biodiversity accounting and valuation of ecosystems. ${ }^{49}$

\subsubsection{Needs and interests}

The fourth CBD report identified the following main threats to Danish biodiversity: cultivation, pesticides, eutrophication, land drainage, overgrowing, high-intensity logging in forests and plantations, straightening and damming watercourses, which has been done in earlier years, and commercial fishing. 50

Denmark is in the early stages of starting up a project for the valuation of ecosystems. The goal of the project is to evaluate and plan how ecologic or nature values should be incorporated into national accounting systems. The project will provide guidance on how this should be done and whether inclusion into GDP is the right path or whether nature values will be considered in some other way on a national level. The most likely path forward will be to include mainly physical stocks and flows into the accounts. A long term goal may be to include monetary values into national accounting, but this will most likely be done when international standards for this have been decided. Denmark is planning to set up a meeting with the EU and EEA on national level accounting. The goal of the meeting is to be able to evaluate how the EU system complements the UN accounting system and to learn what the current development status is and what plans for developing the system exist. ${ }^{51}$

Denmark consideres that it is important that the values should be internationally comparable as an accounting system is set up. At the same time the system should take into account the specific needs of each country as the ecosystems and problems related to biodiversity are different.

The interviews highlighted that it is still too early to define what specific criteria and needs exist for monitoring biodiversity or for ecosystem accounting in Denmark.

\footnotetext{
49 Interview Eva Juul Jensen, Ministry of the Environment.

${ }^{50}$ Fourth CBD report, Denmark, 2010.

${ }^{51}$ Interview, Eva Juul Jensen, Ministry of the Environment.
} 


\subsection{Finland}

\subsubsection{Key national policies and goals}

The National Strategy and Action Plan (NBSAP) for the Conservation and Sustainable Use of Biodiversity in Finland 2006-2016 was adopted in May 2006. It emphasizes the importance of conservation and sustainable use of biodiversity and the fair and equitable sharing of the benefits derived from the use of genetic resources. The Action Plan included a goal to halt biodiversity loss by 2010. This has raised the profile of biodiversity on the political agenda even though the goal was not reached by 2010 .

The present Government of Finland is updating the NBSAP to correspond with the goals of the international Convention of Biological Diversity and the biodiversity targets set in the EU. The updated NBSAP has already been drafted and it will be presented to the government for approval by the end of year 2012. The aim of the NBSAP is to halt the degradation of biodiversity by 2020 . The contents of the NBSAP may still be changed, but the current Government Programme especially emphasizes the protection of threatened species and natural habitat types. It aims to extend the forest biodiversity programme, improve protection of marshlands and conditions of national parks, reform the Fishing Act, create a knowledge base on underwater marine life and identify alternative sources for funding of nature protection.

Finland has ratified most of the international agreements on biodiversity and nature conservation. The Nagoya Protocol on Access to Genetic Resources was signed in 2011, and a review of required legislative changes was published in 2012. There is also a strategy on alien species, which will most likely be compatible with the related EU directive under preparation. The Aichi targets have been included in the national programmes and although they are challenging, Finland has some very good experiences in restoring natural habitats.

According to a review by OECD, Finland has strengthened the integration of nature conservation concerns into national legislation. Positive developments have taken place in the protection of species including migratory species and aquatic wildlife. Management plans have also been established for several game species. 


\subsubsection{Current biodiversity indicators and accounting activities}

The biodiversity indicator system in Finland was notably improved by a joint project started in 2006 between governmental institutions and organizations and environmental NGOs. The developed indicators are presented on a website www.biodiversity.fi including 130 habitatspecific biodiversity indicators. The Fourth National Report on the Implementation of the Convention of Biological Diversity in Finland was based on the use of these indicators. ${ }^{52}$

Biodiversity monitoring in Finland is quite comprehensive with 57 different monitoring schemes. The problem is that the work is conducted and reported by a number of organizations and is not very well coordinated. The data is not always compatible and opportunities for more efficient use of the data may be lost.

The future work on biodiversity accounting will most likely also be based on indicator systems. The main goal is to identify alternatives to GDP accounting. ${ }^{3}$

\subsubsection{Main needs and interests}

The following needs and interests were identified based on the interviews. In terms of environmental priorities, the following issues are topical in the Finnish context at the moment:

- Surface waters and the seas, especially restoration and rehabilitation and data on underwater marine life.

- Old growth forests and virgin forests as well as marshlands, especially in the Southern parts of Finland, where more nature protection areas are needed, and especially voluntary models for private owners are needed.

- Urban issues that have important implications for biodiversity like green areas, storm drainage systems, etc.

There is also a clear need for making a comparison between nature protection areas to define whether the some areas are more valuable than

\footnotetext{
52 Fourth National Report on the Implementation of the Convension of Biological Diversity in Finland. Ministry of the Environment, Finland, 2009.

53 Interview Marina von Weissenberg, November, 2012.
} 
others. This would allow for prioritization between land use in different areas and different usages, for example, between mining, tourism and nature protection. Some non-monetary based methods would also be needed for the assessment of the extent of biodiversity losses versus economic gains. Monetization could be useful in assessing material gains from natural resources and immaterial services.

Ecosystem accounting would be very useful and especially important regionally. Many threats to biodiversity come from local conflicts on spatial planning and local data is needed. Much of this kind of data already exists in Finland, but should be combined in a sensible way, e.g. in spatial statistics.

Alternatives for GDP are clearly needed; finding ways to include biodiversity in the national accounting systems is a priority. Measuring biodiversity in monetary terms is not considered to be useful or interesting. Future developments should be based on indicator systems. In general, there is currently a strong interest in identifying legislation and other incentive systems that conflict with the goals of biodiversity protection. A study on this is likely to be commissioned in the near future.

\subsection{Iceland}

\subsubsection{Key national policies and goals}

The main threats to biological diversity in Iceland are identified as climate change, non-sustainable resource management, ecosystem and habitat degradation, invasive alien species and to some minor extent also pollution.

The Icelandic National Biodiversity Strategy (NBSAP) prepared by the Ministry for the Environment was adopted in 2008. The strategy focuses on a few priority areas for conservation of biological diversity and sustainable use of resources. The strategy contains actions to strengthen the knowledge base for conservation of biological diversity and to improve monitoring. The NBSAP included an action plan for reaching targets set for 2010 . The main foci of the actions are species oriented conservation measures, protected areas, restoration of degraded habitats, actions oriented towards invasive alien species, genetic resources, genetically modified organisms. Also, actions related to information, education and public relations regarding biological diversity were included. 
The goal is to have an updated NBSAP prepared by 2014. Information on status and initiatives is currently being collected for mapping purposes. The ambition is to commence the actual work on the strategy before the parliamentary elections next spring. 54

Part of the implementation of the Convention of Biological Diversity in Iceland is also incorporated into the Nature Conservation Strategy for the period 2009-2013. Its main focus is on protection of species, habitats and ecosystems in line with international agreements. 55 It contains proposals for new protected areas for conservation of biological diversity.

The strategy paper lists the following ten goals:

1. Increased scientific research, registering and mapping of natural history with data collected and stored in accessible databases.

2. Monitoring plans and programmes, and information systems, for biodiversity.

3. CBD targets are to be incorporated in the Nature Conservation Strategy.

4. Marine Protected areas designated to ensure long-term maintenance of sustainable ecosystem services, ecosystems and populations.

5. Laws and regulations related to alien invasive species will be revised.

6. Reclamation and restoration of habitats and ecosystems degraded by land use and construction.

7. Ratification of the Cartagena Protocol on Biosafety under the CBD.

8. Conservation of genetic (and cultural) resources in agriculture.

9. Increased information services and education on biodiversity.

10. International indicators introduced and adjusted to national indicators and conditions.

The Act on Nature conservation is a framework for legislation and sets general criteria for nature conservation and concerns all human interference with nature. The act also forms the main legal basis for protection of areas, organisms, ecosystems and biodiversity. Some other policies which include biodiversity protection are the National Policy on the Oceans and the Master Plan for Hydro and Geothermal Energy Re-

\footnotetext{
54 Interview, Sigurdur Thrainsson, Ministry of the Environment.

55 Source http: //www.eea.europa.eu/soer/countries/is/ soertopic_view?topic=biodiversity, accessed 9.10 .2012
} 
sources. There are also policies targeting land degradation and reclamation, the promotion of the protection of native birch woods and restoration of marshlands.

\subsubsection{Current biodiversity indicators and accounting activities}

The Ministry of the Environment is responsible for developing indicators for sustainable development and sustainable use of natural resources. A number of strategies have been adopted for various issues and sectors.

Currently there is no direct reference in the strategy documents to national level biodiversity accounting. Planning and taking into use national level biodiversity accounting could be set as a target in the next version of the NBSAP in accordance with the Aichi targets. Whether this is done is subject to decisions by the Minister of the Environment. In the next NBSAP Iceland will look into headline indicators, which are related to the Aichi targets. Currently there are no indicators connected with the targets. ${ }^{56}$ However, a number of indicators are followed on a national level with the aim of following-up progress in the area of sustainable development. The indicator system is described in the Ministry of the Environments report Welfare for the future, Iceland's national strategy for sustainable development, Statistical Indicators 2006. The indicators are statistical by nature.

The statistical indicators aim to give an overview of the state of the environment, the strain on nature and wilderness, and governmental authorities' responses to these. The indicators are planned to be further updated in view of the Icelandic government's policy on sustainable development. The goal is to enable the monitoring of progress being made in achieving the set objectives on a regular basis. In addition, new indicators will be developed with the aim of linking environmental affairs to economic and social issues. ${ }^{57}$

The need for indicators to follow up the development of the green economy is also mentioned in the report on the Green Economy published in 2011. The report mentions the need for "green accounting". However, no actions are as yet mentioned that would directly relate to biodiversity.

\footnotetext{
${ }^{56}$ Interview, Sigurdur Thrainsson, Ministry of the environment, Iceland.

${ }^{57}$ Source http: //www.eea.europa.eu/soer/countries/is/soertopic_view?topic=biodiversity, accessed 9.10 .2012
} 


\subsubsection{Main needs and interests}

Biodiversity accounting is seen to be essential in all areas where nature values are monitored. Especially important areas to focus on from an Icelandic perspective are the fishing sector and targeting ecosystem degradation. Presently most terrestrial ecosystems are somewhat degraded in Iceland mainly because of overgrazing. The volcanic activity and related ash deposits, which can be a threat to some ecosystems is a challenge specific to Iceland. Some economic sectors with impacts on biodiversity include the energy industry, fishing, and agriculture as well as infrastructure development.

\subsection{Norway}

\subsubsection{National policies and targets}

Key national targets related to biodiversity, as stated by the Ministry of the Environment, 58 are that a representative selection of Norwegian habitats should be protected for future generations. In addition, major disturbances such as infrastructure development should be avoided in endangered habitats. Important ecological functions should be maintained in vulnerable habitats. The cultural landscape should be managed in such a way that biological diversity, the historical and aesthetic value of the landscape, opportunities for experiencing it and its accessibility are maintained. The needs of future generations should be taken into account when managing soil resources that are suitable for cereal production.

The Convention on Biological Diversity (CBD) provides an international framework for comprehensive management of biodiversity. It focuses on the links between the use and conservation of biodiversity and on the equitable sharing of its benefits. ${ }^{59}$ The government has taken steps in order to ensure that the Norwegian legislation reflects this. A new Act on nature management was established in 2009. The CBD has also had bearings on the development and updating of sectoral legislation. ${ }^{60}$

The Nature Diversity Act applies to all diversity in nature, i.e. for ecosystems, natural habitats, species, and genetic diversity within species'

\footnotetext{
58 Ministry of the Environment, webb site.

${ }^{59}$ CBD status report 4, page 50 .

$60 \mathrm{CBD}$ status report 4 , page 51 .
} 
populations as well as for landscape and geological diversity. The Act has regulations stating which species and habitats are most important for conservation. The Act implies that all sectors that affect or exploit natural resources must put emphasis on common objectives and principles and should minimize negative impacts on biodiversity. The Act emphasises nature's dynamics and the need for differentiated measures, including legislation and economic incentives, in order to reach the national target to halt the loss of biological diversity.

According to the Planning and Building Act, the local authority, in most cases the municipality, ensures that important national and regional considerations are taken into account in the planning process, including considerations on biodiversity. ${ }^{61}$

The Management of Wild Marine Resources Act came into force in 2009 and it concerns all wild living marine resources and their genetic material. The purpose of the Act is to secure the sustainable and socioeconomically profitable management of wild marine resources and associated genetic material and to contribute to securing employment and settlement in coastal communities.

\subsubsection{Current biodiversity indicators and accounting activities}

Selected indicators are reported in the National Sustainability Indicators, which are included in the annual National budget of Norway reported to the parliament. Many other indicators are included in the Ministry of the Environment's national reporting system, such as in annual reports to the parliament. Much is under development regarding e.g. how CBD Aichi Targets and the Ministry of the Environment's national environmental targets can be monitored and reported. Monitoring programs are in place for many biodiversity elements, but there is still a need for refinement and development, not least on ecosystem service related aspects.

Most of the targets are established in the Ministry of the Environment and there may be a need to develop a set of more coherent national targets aligned and rooted across ministries and sectors. This could also form the basis of a more coherent reporting system, which can be used for different policy areas and for accounting purposes where appropri-

${ }^{61}$ CBD status report, 4 page 51. 
ate. Efforts coordinated by the Directorate of Nature Management ${ }^{62}$ are underway to prepare input for the Ministry of the Environment on opportunities and challenges/gaps related to reporting on Aichi Targets at the global level and SEBI/EEA at the European level.

An expert commission was established in October 2011 on values of ecosystem services. As part of its mandate, the commission looks at ways of estimating or calculating values of ecosystem services as part of Norway's national wealth, including and pros and cons related to incorporating biodiversity values into national accounting systems. The commission will provide its report to the government on 31 August 2013.63

Current biodiversity and ecosystem service related accounts, statistics and indicators in Norway include the following: 64

- National accounts following SNA: Includes information on market and near-market monetary aspects related to production of biological resources (provisioning services) from agriculture, forestry and fisheries/aquaculture.

- Formal satellite accounts: Some in place on pollution, and some under development on waste and energy.

- Accounts and statistics efforts following SEEA: Statistics Norway produces statistics and accounts on several elements. Some are in place on pollution and water use, and some under development on waste and energy. There is also measurement of environmental efforts and harmful subsidies (i.e. on policies and instruments). Statistics Norway participates in work on SEEA experimental accounts on ecosystem services.

- National wealth: Statistics Norway does experimental work on identifying role of different types of capital as part of national wealth, including role of natural capital.

- National budget: The national budget, which is presented annually to the parliament, includes a set of sustainability indicators, including elements on biodiversity (from the Nature Index) and biological resources.

- Nature Index: The Index has been developed to follow status and development of biodiversity in Norway for the main

\footnotetext{
62 Direktoratet för naturförvaltning.

63 The mandate for and more information on the commission is available (in Norwegian and English) at www.regjeringen.no/okosystemtjenester

64 Source Interview.
} 
ecosystems. ${ }^{65}$ The Nature Index measures the state and trends for biodiversity in major ecosystems using more than 300 indicators. Indicators are chosen from a variety of species groups for each ecosystem, and they are used to measure deviation from a reference state, which is intended to represent ecological sustainability. All indicators and the overall Nature Index have values between 1 (for the reference state) and 0 (very poor state). The first edition of the Nature Index was published in 2010. 66

- Norway also reports some indicators to SEBI 2010.67

\subsubsection{Main needs and interests}

The general target of the relevant policies in Norway is to stop the loss of biodiversity. The need for especially good monitoring and follow-up has been identified for especially fishing management and endangered species. ${ }^{68}$

Altered land use is the most significant factor impacting Norwegian biological diversity. This is the predominant threatening process for $85 \%$ of the red-listed species in the country. The second most threatening factor is pollution (6\%). Climate change is thought to pose a similar sized risk as pollution. Exploitation is the main hazard to $1 \%$ of the species, but affects mainly key critical species within ecosystems. ${ }^{69}$

The Norwegian accounts are so far mostly physical accounts. ${ }^{70}$ The connection to economic and societal value is still missing for most biodiversity elements and ecosystem services. A need has been identified for strengthening the understanding and knowledge of the link between biodiversity and production of resources and services, and for linking this to welfare and human well-being.

Monitoring of biodiversity targets should be developed. There is also a need for better alignment between "environment and sector" targets, where the entry points for biodiversity (at different levels and including biological resources) may be different, but should be coherent.

\footnotetext{
${ }^{65}$ Further information at http://www.dirnat.no/naturindeks/

66 http://www.environment.no/Topics/Biological-diversity/The-Norwegian Nature-Index-/

${ }^{67} \mathrm{CBD}$ status report 4 page 8.

68 Source Interview.

${ }^{69}$ CBD status report 4.

${ }^{70}$ In additiion there are numerous spattial mapping and for instance follow-up of endangered species (Red list) etc.
} 
Likewise, there is also need for monitoring ecosystem service targets. The targets should reflect different value aspects, including economic values both from the "environment" side and the "sector" side, including food, energy, health, security, well-being, climate adaptation and mitigation, etc. There is a need for better alignment between "environment and sector" targets. The entry points for different ecosystem services may be different, but should still be coherent.

In addition to OECD's criteria for good indicators, some important criteria in designing indicator systems are that there should be a link between biodiversity and economy and that the linkages are explicit. There should also be indicators which are linked to the production of resources, for example, linking marine resources to economic production. There needs to be a widened understanding especially of regulating services such as flood mitigation, water purification and pollution control as well as cultural services and their role in ecosystems.

When indicators for biodiversity are considered, they should measure biodiversity and the indicator should say something meaningful. The indicators should tell something of the health of an ecosystem. Key species should be used as indicators for the health of ecosystems and the indicators should be sensitive to change. From a management perspective the indicators would need to be an early warning system, which will indicate if something will merit a closer look.

Indicators can contribute to monitoring environmental trends over time or reflect distributional patterns in space. In the context of biodiversity management, indicators should help to guide decision-making processes. Ideally, indicators should tell a story and help to communicate ideas.

\subsection{Sweden}

\subsubsection{National targets and policies}

The Swedish environmental policy is formulated in a set of Environmental Objectives that have originally been approved by the Swedish Parliament in 1997. The fifteen Environmental Objectives include six objectives focusing on biodiversity of a certain nature type (freshwater, the marine environment, wetlands, forests, agricultural landscapes and mountains) and one objective that includes biodiversity as one of the main aspects (the built-up environment). The remaining eight objectives cover threats to the state of the environment. In 2005, a sixteenth Objec- 
tive was added called 'A rich diversity of plants and animal life'. This was done in order to deal with those aspects of biodiversity that may not be included in the sectoral approaches. The system of Environmental Objectives includes both long term objectives and interim targets, which are regularly being updated. ${ }^{71}$

The EU's 2010 target of halting biodiversity loss has been incorporated into the 16 Environmental Objectives, although the target was not met by 2010 . The Swedish government has since initiated several activities to protect biodiversity: more valuable forest areas have been protected, species' action plans have been produced and implemented and a national strategy and action plan for alien species was approved already in 2008.72

Although the concept of an ecosystem approach is not very widely known or used in Sweden, discussion on the sustainable use of resources has increased. The concept of sustainable use has proved difficult to define and operationalise and proper mechanisms to enhance it amongst foresters, farmers and other actors are still lacking. ${ }^{73}$ There is an interim target on biodiversity and the value of ecosystem services set in 2012 . The Ministry of the Environment is currently working on how ecosystem services' value to society can be made more visible. In 2012, a decision was made to introduce clarifications and interim targets to the system of environmental objectives. In connection to this, the Swedish Government has stated that Sweden should make a clear contribution to achieving the EU Biodiversity Strategy to 2020 and the strategic goals of the Nagoya plan. ${ }^{74}$

\subsubsection{Current biodiversity indicators and accounting activities}

Sweden participated actively in the project SEBI 2010 (Streamlining European Biodiversity Indicators) coordinated by the EEA. The project produced a set of 26 indicators based upon the decision VIII/15 of the Conference of Parties Convention. Most of these indicators dealt with information that already existed within the system of indicators of the

\footnotetext{
${ }^{71}$ Fourth National Report on the Implementation of the Convention of Biological Diversity, Sweden, 2009. 72 Fourth National Report on the Implementation of the Convention of Biological Diversity, Sweden, 2009. 73 Fourth National Report on the Implementation of the Convention of Biological Diversity, Sweden, 2009. ${ }^{74}$ Swedish Government Newsletter 18.10.2012, available at http://www.government.se/sb/d/14471/a/201906
} 
Environmental Objectives. ${ }^{75}$ These indicators, which are mainly physical accounts, are collected and updated by a number of different agencies. The Bureau of Statistics is mainly responsible for the collection of this data. No monetary accounts exist at the moment. Sweden is also considering participation in the WAVEs project, but is not yet a partner. ${ }^{76}$

\subsubsection{Main needs and interests}

Currently the main interest is the valuation of biodiversity and ecosystem services also in economic terms. There is a need for economic models which would show how economic activities are dependent on ecological services or goods produced from ecological services. A merging of ecological and economic models may be fruitful in order to identify interactions and interdependencies, for example, to show the change in production of goods or services as a function of ecological services. It would be important to estimate the costs of inaction and to make the case for business to involve itself in biodiversity protection.

In general, the priority should be in creating good quality indicators that would emphasise quality in addition to quantity. For example, in addition to their number, the welfare and quality of forests should be emphasised. Environmental priorities in the case of Sweden could be overfishing, reducing nutrients (e.g. NOx), and protection of forests and wetlands.

\subsection{Summary of the Nordic needs and selected assessment criteria}

The five approaches will be assessed against criteria partly derived from the Nordic countries' needs identified through the desk study and the policy-maker interviews (summarized in Table 4.1. below). The policy objectives included in the table have been ranked by interviewees as low or high priorities for their country.

\footnotetext{
75 Fourth National Report on the Implementation of the Convention of Biological Diversity, Sweden, 2009.

76 Interview Jessica Andersson, Environmental Protection Agency, Sweden, 26.10.2012.
} 
Table 4.1. Framework for the identification of policy objectives/needs and subsequent assessment of relative priority.

\begin{tabular}{|c|c|c|c|c|c|}
\hline Policy objective / need & Denmark & Finland & Iceland & Norway & Sweden \\
\hline $\begin{array}{l}\text { Mainstream biodiversity } \\
\text { across sectors of the } \\
\text { economy }\end{array}$ & & Yes & $4-5$ & Yes & 4 \\
\hline $\begin{array}{l}\text { Reduce the use of re- } \\
\text { sources that indirectly } \\
\text { result in biodiversity loss } 77\end{array}$ & 3 & Yes & 5 & Yes & 4 \\
\hline $\begin{array}{l}\text { Reduce pollution harmful } \\
\text { to biodiversity }\end{array}$ & 3 & Yes & $1-2$ & Yes & 4 \\
\hline $\begin{array}{l}\text { Halt the loss of ecosys- } \\
\text { tems/Restoring degrad- } \\
\text { ed/lost ecosystems }\end{array}$ & 4 & Yes & $4-5$ & Yes & 4 \\
\hline Halt the loss of biodiversity & 5 & Yes & $4-5$ & Yes & 5 \\
\hline $\begin{array}{l}\text { Halt the loss of specif- } \\
\text { ic/protected habitats }\end{array}$ & 4 & Yes & $4-5$ & Yes & $4-5$ \\
\hline $\begin{array}{l}\text { Halt the loss of ecosystem } \\
\text { services (e.g. halt loss of } \\
\text { carbon storage in peat- } \\
\text { lands) }{ }^{78}\end{array}$ & 4 & Yes & $4-5$ & Yes & \\
\hline $\begin{array}{l}\text { Provide a basis for adjust- } \\
\text { ing GDP for the degrada- } \\
\text { tion of ecosystems/loss in } \\
\text { natural resources }\end{array}$ & 3 & $\begin{array}{l}\text { Include, but } \\
\text { possibly not } \\
\text { in economic } \\
\text { terms. }\end{array}$ & & $\begin{array}{l}\text { SNA includes } \\
\text { indicators. } \\
\text { Monetary value } \\
\text { not planned to } \\
\text { be included. }\end{array}$ & $\begin{array}{l}\text { Not sure if } \\
\text { this is a goal } \\
\text { in Sweden. }{ }^{79}\end{array}$ \\
\hline $\begin{array}{l}\text { Demonstration of the value } \\
\text { of biodiversity }\end{array}$ & 3 & $\begin{array}{l}\text { Important. } \\
\text { How, is still } \\
\text { not clear }\end{array}$ & & Planned & $\begin{array}{l}\text { Incorporate } \\
\text { into targets } \\
\text { for } 2020 \text {. }\end{array}$ \\
\hline
\end{tabular}

Colour coding: From the interviews Red: very high priority, Dark orange: high priority, Light orange: moderate priority Green: low priority. White: no information available/not rated. The numbers indicate the importance ( 1 not a priority and 5 very high priority). The answer Yes for Finland and Norway indicate that this is a priority, but that it has not been rated in the interviews.

The table reflects the views of the interviewees, which indicate that most policies and goals have a high or relatively high priority in all of the Nordic countries. The differences mainly lie in where challenges have been identified, what pressures exist and what ecosystems are under threat.

${ }^{77}$ E.g. through land use changes by for instance development of transport infrastructure and fragmentation, urban sprawl etc.

${ }^{78}$ Comment from Sweden: This is a new concept. The ecosystem services will be identified. (Stated in the 16 targets). In 2-3 years this thinking will become more mainstream.

${ }^{79}$ Sweden tried this earlier and came to the conclusion that it didn't work. 
The interviewees in Norway and Sweden and Finland have not seen the need to adjust the GDP with the monetary value of ecosystem degradation, biodiversity related value or loss of natural resources. In Norway the official view is that biodiversity and sustainability can be incorporated into National accounts as indicators. The indicator used so far in Norway is the Nature Index. Denmark considers it most likely that stocks and flows will be included, but that inclusion of monetary value could be one possibility in the future if international standards are developed for this and are generally accepted.

\section{Selected criteria and needs related to biodiversity and ecosystems related indicator and accounting systems from a Nordic perspective}

As a starting point, the interviewees mentioned that when choosing or designing indicators, the OECD criteria should be fulfilled. In addition, indicators should also meet the SMART ${ }^{80}$ criteria.

Some of the criteria and needs, which were identified in the interviews with policy-makers and are seen as reflecting the measurement needs (relating to indicators and accounting) from a Nordic perspective, are outlined below. It is worth pointing out that these are based on a limited number of interviews and in some cases, these reflect the personal views of the interviewees.

A. Linking biodiversity to economy.

$\circ$ Identifying the biodiversity economy link and making the linkages explicit.

- Ability to measure how production is dependent on the ecosystem services: a merging of the ecologic and economic models. Interactions and dependencies should be shown.

B. Linking accounts / indicators to human wellbeing or welfare.

- The indicators or accounts should have a link to human welfare.

- Today mostly transactions are measured, not welfare.

C. Comparability and equivalence.

- Would be good if there could be equivalence for comparing for instance emissions, pollution, fertiliser runoffs and harmful substances.

${ }^{80}$ According to which indicators should be Specific, Measurable, Attainable, Relevant and Timebound). 
- Finding objective ways to assess and to rank for instance nature conservation areas or land areas.

D. Validity.

- When biodiversity is monitored the indicators should actually measure biodiversity - the indicator should bring meaningful information.

- The link to biodiversity should be as direct as possible.

E. Quality of the ecosystems should be measured.

$\circ$ The indicators should tell something of the health of an ecosystem.

F. Link to policies.

- The indicators/accounts should be possible to link to policies.

- The indicators/accounts should be possible to be used for policy making and follow-up of policies.

- Targets should be possible to be set and followed-up on the appropriate level (local, regional, national).

G. Indicators should function as an early warning system.

$\circ$ The indicators should be sensitive to change and should indicate if anything should be done or merits a closer look.

H. Functional importance.

- Key species which reflect the health of an ecosystem should be used as indicators.

I. The indicators or accounts can be used to communicate ideas.

- The indicators tell a story and can be used to communicate.

- Indicators/accounts should be understandable. 


\section{Analysis of biodiversity accounting systems in light of Nordic countries' needs}

\subsection{Presentation of the criteria in light of which the approaches were assessed}

The needs expressed in the interviews with policy-makers in the Nordic countries were translated into a range of criteria against which each one of the approaches was assessed. The identified needs can be reflected against different needs for data and information at different stages of the policy cycle.

Figure 9.: The policy-cycle and its different stages

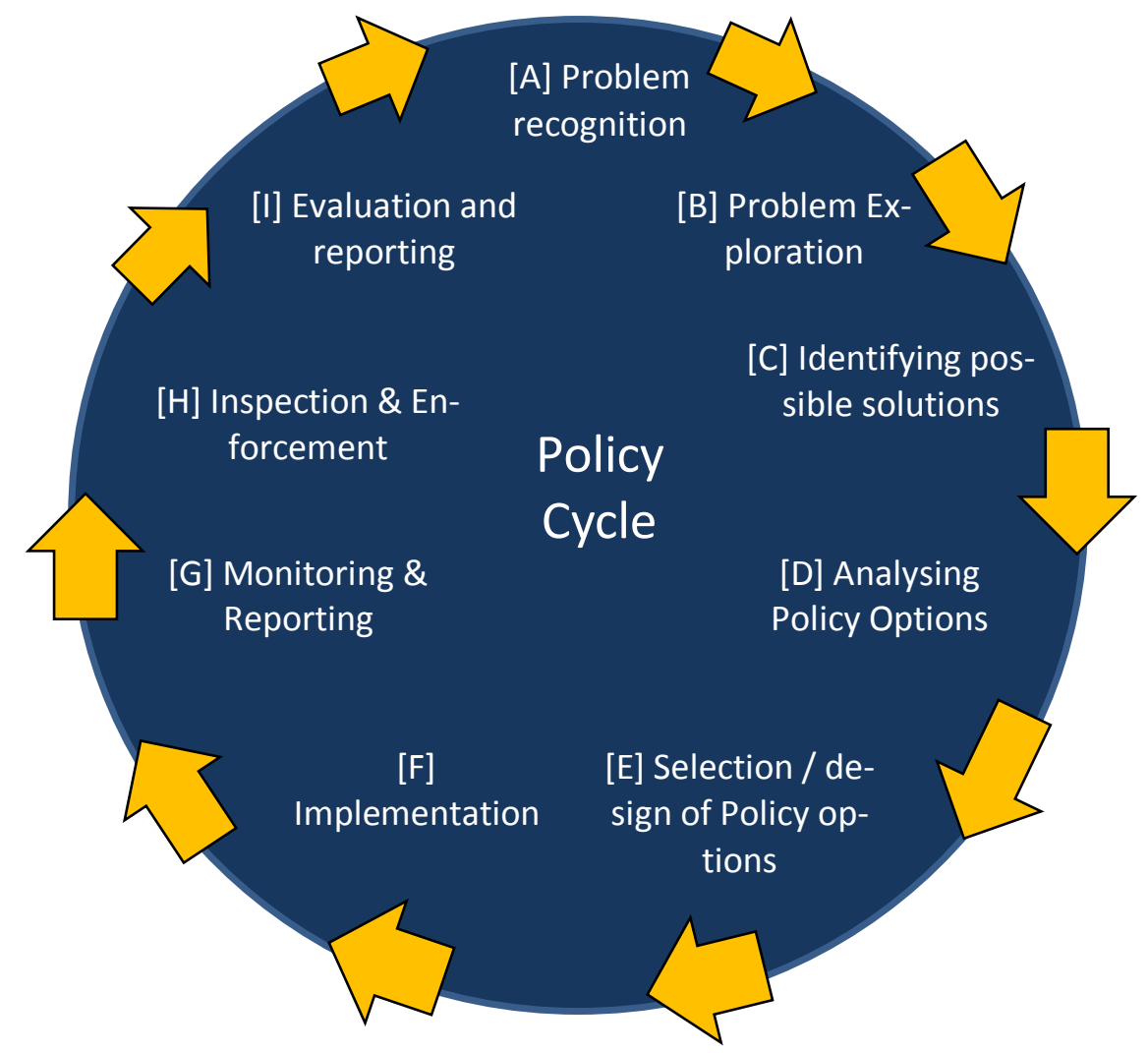


The different stages of the policy cycle, together with the RACER evaluation framework (see further down for more detail on this), were therefore used as a way to structure the assessment of the approaches.

As regarding the criteria reflecting more specifically the information needs across the policy-cycle, the criteria chosen reflected the following concerns and expectations for the approaches to accounting for natural capital:

- Usefulness to support in problem identification, exploration and policy development [Policy cycle stages A, B, C,D].

- Usefulness to support the development of policy-relevant indicators, target setting, reporting and monitoring [policy cycle stages E, G, I].

- Usefulness to support the implementation of policy, especially landuse decisions [stage $\mathrm{F}$ ].

In addition, it is worth highlighting that many of the needs expressed suggested that a whole range of policy-makers primarily consider the accounts as a means to serve the development of policy-relevant indicators to be used in the pursuit of biodiversity policy objectives. The extent to which the approaches were suited to provide information to answer five key questions regarding the implementation of the Convention on Biological Diversity (CBD) according to the CBD Secretariat therefore also underpinned the criteria development for the assessment of the five approaches to accounting for natural capital:

1. What is changing and to what extent? (state).

2. Why is it changing? (pressure/threat).

3. Why is it important? (use);

4. What are we doing about it? (response).

5. Do we have the means to formulate and implement response measures? (capacity).

The set of criteria derived from the RACER evaluation framework further helped assess the approaches for their strength and weaknesses as regards their:

- Relevance - i.e. closely linked to the objectives to be reached.

- Acceptance - e.g. by staff and stakeholders.

- Credibility for non experts, unambiguous and easy to interpret.

- Easiness to monitor (e.g. data collection should be possible at low cost).

- Robustness - e.g. against manipulation. 
Ultimately a list of 37 criteria was drawn up and a simple scoring system developed to help identify the approaches that would fulfil most of the Nordic countries needs as expressed in the policy maker's interviews and the desk study (see chapter 4). The questionnaire that was used to systematically review the extent to which each one of the approaches met the needs of the Nordic countries can be found in Annex I. Section 5.2. below presents the results of the assessments approach by approach and concludes by highlighting the needs that each one of the approaches appears most suited to respond to.

\subsection{Synthesis assessment of the five approaches taking into account Nordic context}

In the sub-section 5.2.1. to 5.2.5. below, the main findings relating to the following aspects for each one of the approaches are summarised:

A. Usefulness to support in problem identification, exploration and policy development.

B. Usefulness to support the development of policy-relevant indicators, target setting, reporting and monitoring.

C. Usefulness to support the implementation of policy, especially landuse decisions.

D. Robustness, Understandability, Practicability, Credibility, Acceptance

E. Total scoring.

\subsubsection{SEEA Central Framework and its implementation as promoted by the WAVES partnership}

\section{Usefulness to support in problem identification, exploration and policy development}

The monitoring of resource flows into the (national) economy is a core part of the SEEA Central Framework - its physical supply and use tables and asset accounts are particularly useful for monitoring a whole range of resource stocks and flows. The harvesting and extraction of some of these resources, such as timber, are known to potentially have significant adverse impacts on biodiversity. So, to the extent that information on the impacts on biodiversity associated with these different resources exists, indirect links with resource use and biodiversity loss can be established and trends in the use of these resources monitored. Associated with life-cycle analysis data on impacts associated with certain goods 
and the extraction of certain resources can help develop an understanding of the more exact composition of the resource uses underpinning a country's 'ecological footprint'. The SEEA also allows linking the flow of resources to specific sectors of the economy. This may help policymakers identify priority areas for action for reducing the use of resources that result in the most adverse biodiversity impacts.

Furthermore, pollution and waste accounts help monitor emissions of substances that are harmful to both biodiversity and humans.

The SEEA Central Framework (SEEA Volume 1) is not a fully suitable framework for establishing a direct link between biodiversity/nature and the economy as it only captures the benefits derived as far as they are traded on markets and formally enter the economy. This means that, with the exception of a few provisioning services (timber, fisheries) most ecosystem services remain invisible. Other data that is not part of this framework would be needed to demonstrate the link between ecosystems and the provision of these services. So, all in all, regulating and cultural services are not part of the framework and the SEEA Central Framework is not suitable for monitoring most ecosystem service flows to different types of end-users (sectors, households, etc). The sectoral classification and more specifically the functional accounts which register environmental activities and related flows can help develop an improved understanding of the number of jobs associated with nature and ecosystems to the extent to which certain sectors depend more or less directly on nature or on improving environmental quality (e.g. environmental goods and services sector).

\section{Usefulness to support the development of policy-relevant indicators, target setting, reporting and monitoring}

As far as the targets are linked to the accounts that are part of the SEEA the SEEA can indeed provide a framework for setting targets and monitoring trends. While the focus of the accounts is on the national level, such targets can also be set at the regional level, provided the data is available. Hence, targets aiming at reducing the use of specific resources in the economy could be set and monitored, as could targets relating to the flows of materials and energy that leaves the economy (residuals) including solid waste, waste water and emissions to air, water and soils.

The SEEA is not suitable for setting targets in the area of ecosystem resilience or ecosystem quality. It does not monitor the trends in the status of specific species. While it may be used to monitor trends in the use of certain assets over time, it can't be used to monitor the stock of different types of ecosystems as these are not recorded in the SEEA. 
As regards overall macro-economic monitoring, the approach would be quite essential for any attempt to adjust GDP for depletion of assets, but would have severe limitations for the foreseeable future (and arguably also beyond) as regards taking into account the deterioration of ecosystems and biodiversity.

\section{Usefulness to support the implementation of policy, especially land-use decisions}

While the SEEA cannot be used to model potential impacts of specific policy options, it is a suitable framework for collection of much of the data that would be input in such models. Provided that causal relationships and correlations can be duly established and that policies meant to impact some of the accounts that are part of the SEEA, the data collected via the account could help monitor (some of the) impacts of a policy over time. Although the approach may include the development of land cover accounts as well as soil resources it is not really suited to support the designation of land for specific purposes (e.g. development, protection, restoration, etc.). In principle, the SEEA framework can be adapted to each country's administrative boundaries - what ultimately matters is the availability of the data at the level at which it gets implemented - the national level tends to be the one at which the kind of data to feed into the SEEA is collected.

\section{Robustness, Understandability, Practicability, Credibility, Acceptance}

The SNA links to the System of National Accounts and therefore has a sound theoretical base. It is based on real word data rather than modelled data, which suggests that it has solid empirical roots. Furthermore, the approach has been applied in many countries and a whole range of the accounts have been in use and tested for a number of years already. Most countries have however focused on applying the specific parts of the SEEA that they had a specific interest in. The data which feeds into the SEEA tends to be widely accessible, for the most part - although some of the data is provided by industry in the context of non-disclosure agreements between statistical offices and the industry. 


\subsubsection{Measuring Ecosystem Goods and Services (MEGS)}

\section{Usefulness to support in problem identification, exploration and policy development}

MEGS measures the ecosystems themselves rather than their use. The classification of ecosystems combines information on land cover, elevation and 'rugosity' (i.e. level of disturbance of the land).

The MEGS tracks changes in land coverage ecosystem units using national scale satellite imagery and a basic statistical unit of 250x250 sq. meters. This results in maps identifying different types of ecosystems. Various sets of information that are more precise may be combined with these maps, as far as the information is available.

Ecosystems are valued in the context of the MEGS, but this is done to get an idea of the benefits that are drawn from those ecosystems rather than to measure the use of these ecosystems by specific sectors of the economy.

The ultimate objective is to allow the establishment of a link between the MEGS accounts and the SNA, thus creating links between biodiversity/nature and the economy. In so far as information on the biodiversity exists the MEGS could also help establish links between biodiversity and the availability of resources/services but it must be pointed out that in Canada, at this stage, there is a lack of information on biodiversity.

The approach includes an identification of ecosystem services across the landscape and can therefore, in combination with other sets of information that can be included in the mapping, contribute to an improved understanding of how provisioning, regulating and cultural ecosystem services relate to the economy, could help monitor the flows of ecosystem services over time to different households or account for the factors that directly contribute to human welfare.

\section{Usefulness to support the development of policy-relevant indicators, target setting, reporting and monitoring}

The approach may provide information relative to the quality/resilience of ecosystems as it may monitor how ecosystem may change over time: by looking at the land use change matrix, changes in an ecosystem over time may be observed. The approach is therefore suitable for monitoring the stocks of different ecosystems over time as well as monitoring the flows of ecosystem services over time and space. 
As regards ecosystem services, the MEGS relies on the CICES ${ }^{81}$ (internation classification of ecosystem goods and services) - land cover types are associated with certain ecosystem services. This results in a map of the country identifying, for each pixel, which services are provided by the land. The next step that could provide insights into ecosystem quality would be to develop a net landscape ecosystem potential indicator - measuring the services that the ecosystem ought to provide - and to get an insight into the ecosystem's quality by comparing this with a measurement of the services that the ecosystem does actually provide in reality.

The approach will not allow adjusting GDP in the short term because that would require quite some work in the area of valuation of the ecosystems. Some work is being done on the valuation using market values and replacement costs but this is far from providing values expressed in monetary terms that could serve to adjust national wealth.

\section{Usefulness to support the implementation of policy, especially land-use decisions}

The approach arguably cannot serve to model the likely impacts of specific policy options. As the approach results the stocks of different types of ecosystems it could, however, serve to monitor the impacts of policies targeted at specific ecosystem types, such as a policy aiming at restoring the integrity of an area over time. - the change in land coverage and change in quality could be monitored. Similarly, policies aiming at a stabilisation of biomass extraction at specific levels could also be monitored if different layers of information available at different levels were added up/combined (levels including ecodistrict, ecoregion, ecoprovince, ecozones).

If the capacity of ecosystems to provide specific ecosystem services was a criterion for the designation of land for specific uses, the MEGS could help identify which areas (or ecosystems) to designate/protect. Already at this stage, the different hierarchy levels of protection of the land can be integrated into the MEGS. Furthermore, it can incorporate data produced bottom up, from the local level, which allows also for more refined pictures where data is available. This also implies that it can relatively easily be adapted to each country's administrative boundaries.

${ }^{81}$ CICES - Towards a Common International Classification of Ecosystem Services, URL: http://cices.eu/ 
The MEGS accounts for the spatial variability of ecosystems by doing the binary link for each one of the ecosystem land cover types - this allows knowing which ecosystem services should be available and where.

It is one of the aims of the MEGS to make progress in the area of valuation of ecosystem services and to recommend methodologies to be used for the different types of ecosystem services.

Robustness, Understandability, Practicability, Credibility, Acceptance MEGS is a data driven project. Mostly, satellite imagery is combined with a lot of different layers of information and data such has other geographic products including river network, wetlands. Much of this data is robust and has been collected for a long time. The approach has not been used much, given that MEGS are still experimental accounts. At the end of 2013 a publication will present in more detail the results of the MEGS project. At this stage, some of the indicators have already been calculated and some materials have already been produced.

Although the approach is relatively simple, it is too early to say how easy it will be to communicate and to which extent policy-makers will find it a useful tool. The approach has, however, already attracted quite some interest in important fora in expert community. So while the approach is not yet widely endorsed, the results are likely to be an important contribution to the SEEA Volume 2 on experimental ecosystem capital accounts and the approach can be considered flexible enough to be usable in countries with different ecosystems.

\subsubsection{EEA's Ecosystem Capital Accounts (ECA)}

\section{Usefulness to support in problem identification, exploration and policy development}

The ECA may allow identifying and monitoring the use of some resources that indirectly result in biodiversity loss - more specifically biomass extraction and water use. However, it doesn't do so at a very disaggregated level and the "biomass" account, for example, is not broken down in its many constituent parts (i.e. it does not distinguish different types of biomass). It is therefore likely that the accounts will result in numbers on total biomass harvesting, but it is not entirely clear to which extent this will allow sustainable biomass extraction levels to be determined and therefore the level of pressure on biodiversity.

The ECA can, to a certain degree provide information on the capacity of an ecosystem to deliver services/resources: knowing the biomass or carbon stock as well as the water balance can give good indications into 
potential ecosystem service flows. Pending the availability of other socio-economic datasets or information layers (e.g. population centres) that could be combined with the ECA, insights into the links between ecosystems, their characteristics (e.g. biodiversity level) and the economy/human well-fare (e.g. health benefits) could be provided. However, at this stage (and expected 2014 version), ECA is far from covering all ecosystem services. Also, initially, information on food crops and timber, will only be provided as stocks and no market values will be provided a further limitation to linking clearly the ECA to the SNA.

At this stage the links between the ECA, the SEEA and the SNA are too weak to guarantee links that would allow ECA to help identify sectors that result in significant pressures on biodiversity.

Specific components of the ECA could potentially be used as early warning systems: where ecological thresholds are known, some of the accounts (especially water related) may show that there is a trend that brings you closer to these thresholds - the latter needs however to be determined outside the ECA framework. This does of course assume time series providing a longer term perspective as regards issues such as carbon content in soils, changes in land use types etc. It is however foreseen that the 2012 ECA will already have 2000-2010 time series data and in the long run the data should be updated on a 2-3 year basis.

\section{Usefulness to support the development of policy-relevant indicators, target setting, reporting and monitoring}

Provided there is information on critical thresholds and that the expressed units can be linked to the ECA accounts, it could be possible to use some of the accounts to monitor targets related to the critical thresholds to be avoided. The areas where such target setting based on the ECA appears most straightforward at this stage are water over extraction and carbon storage (in the context of ecosystems such as peatlands). However, ECA does not aim to assess biodiversity loss and threshold, as this needs to be done through ecology indicators and analysis the biodiversity loss and thresholds.

The ECA should allow monitoring the stocks of different types of ecosystems over time, although initially this is likely to be only a restricted number of ecosystems. The ECA should also allow monitoring the flows of specific ecosystem services via its carbon and water accounts. Time series can capture carbon sequestration.

Similarly, the ECA could be used to provide insights on the quality/resilience of an ecosystem, where there is underlying knowledge of the factors that the ecosystem quality and resilience of a given ecosystem depend on. For example, trends in water availability could help un- 
derstand whether a wetland is drying out, degrading and at risk of passing an ecological threshold. In some cases low carbon storage values will indicate degradation. The ECA does not allow monitoring the resilience/health of specific ecosystems via the monitoring of specific species - similarly, none of the accounts are suitable to monitor the status of biodiversity of species over time. This information is provided separately via biodiversity indicators.

The ECA could help adjusting GDP for the deterioration of ecosystem and biodiversity loss in the medium term, but this would be more in the form of providing support though quantitative information suggesting that an adjustment would be justified rather than through the provision of the data in a format that would allow to actually adjust GDP. If methods improve to be able to better measure ecosystem degradation / ecological debt and associated loss of value, then there is potential to estimate a value for degradation/depreciation of the natural capital stock that could be used to adjust GDP. This remains, however, not a short or medium term likelihood or ambition.

\section{Usefulness to support the implementation of policy, especially land-use decisions}

The ECA is arguably not useful for modelling into the future - it only collects information on the past and current ecological reality. So it cannot really be used to model potential impacts of specific policy options. However, it may help giving insight on the potential consequences of policy choices. For example, it could provide the necessary data to calculate the required increase in imported food as a result of an increase in biofuels production (and the resulting substitution of food crops). Similarly, with the exception potentially of major policies, ECA cannot really serve to monitor, with any accuracy, the impacts of a specific policy over time - causal chains and proven correlations would be needed and will be very difficult, if not impossible, to establish.

The ECA could, however, help inform land use planning as various parameters from its account could overlap in maps, highlighting critically important or sensitive areas. It may well be, however, that other tools are just as good as the ECA for doing this, especially at the local level, where further information and data could possibly feed into an analytical framework/tool.

The ECA data is primarily meant to be used for European level analysis and it adopts a top-down approach (i.e. it collects data available at the international and European level). While locally collected data may help improve the ECA, it is unlikely that the ECA will help improve locally available data and maps that have been developed for 
planning uses at the local level. The ECA may not be precise enough to be used in such a way, as data are provided for a one square kilometre grid. At this stage, it is not yet sufficiently integrated with other accounts, such as economic accounts, to justify its use as the framework in which local data is to be integrated for spatial planning purposes. At higher tiers of governance and for more strategic planning it could still prove useful, especially since all data is converted in $1 \mathrm{~km}$ grids and this can be used in the countries with the country's data - allowing both comparability and national relevance.

\section{Robustness, Understandability, Practicability, Credibility, Acceptance}

The ECA has a sound theoretical base - indeed a lot of effort has gone into understanding the theoretical foundation and the ecology of it. The ECA rests on the best possible European data and much effort is going into statistical validation. However, the objective is not to provide a picture that will be $100 \%$ accurate down to the very local level at this stage. Hence, rather than empirical in its roots it currently relies heavily on modelling, though there is potential for increased calibration and use of local empirical data over time. Given that the use is primarily to be for analysis at European scale, only selective tests to check whether the ECA is consistent with national data are foreseen for the moment. Although the ECA approach in itself has not been applied, a whole range of the accounts and data sets on which it rests have been used in different contexts and hence already undergone a verification process. While the ECA approach is not yet widely accepted, the need for the tool and its importance is widely recognised and the expert community is keen to see the ECA develop and be applied.

The ECA is relatively complex from a technical perspective and therefore not easy to communicate. The rationale behind the ECA and what its uses are can however be easily illustrated and communicated to non expert audiences.

It is foreseen to make much of the data available to encourage national experimentation and this is likely to result in the approach being broadly compatible with an "open data" approach. 


\subsubsection{InVEST tool and the Natural Capital project's approaches more generally}

\section{Usefulness to support in problem identification, exploration and policy development}

The InVEST tool uses habitat maps and land use cover maps as primary inputs. Hence, it may be used to identify the use of resource that indirectly result in biodiversity loss as far as the resource extraction that has impact on biodiversity is captured in the land use cover maps. This does work better for some types of land uses (i.e. transportation corridors and mining, which are well reflected) but some are less well captured (e.g. dams and impacts on freshwater).

Concretely, this means that the InVEST tool will primarily help in identifying economic sectors that result in pressure on biodiversity as far as their activities are spatially connected. In certain areas the InVEST tools allow the user to highlight how ecosystems positively contribute to the economy via ecosystem services - all the models within InVEST have an optional economic valuation model although not all ecosystem services can be used here. As regards provisioning services, on the terrestrial side, timber and hydropower productions can be included in the models. In the next year, agricultural crops production as well as lifestock should be added. On the marine side, fisheries and aquaculture can be included. As regards regulating services, it is foreseen that flood mitigation and pollution regulation (relating to water) will be integrated into the tool and recreation and tourism for cultural services (in the marine environment, aesthetic quality will be factored in too).

The model requires identifying beneficiaries of the services, thus making it relatively interesting for the establishment of payment for ecosystem service tools. The developers of the tool are currently working on factoring in work/jobs, most probably via reduced health risks and implications for the reduction of lost days at work.

The InVEST tool is only to a limited extent suited for monitoring emissions/pollution and/or other harmful substances. The capacity of ecosystem to regulation of pollution is captured. Hence, direct pollution inputs show as far as they have detrimental impacts on this capacity. 


\section{Usefulness to support the development of policy-relevant indicators, target setting, reporting and monitoring}

The tool can be used for scenario analysis - as for instance projected ability to meet specific targets. One does however have to feed the appropriate data into the tool - the tool does not generate data. But if the data that has been feed into the tool reflects changes, this may provide information as regard the trends relevant to a specific target. When it comes to measuring ecosystem quality/resilience, the tool is not really designed to do this, but it might be possible to use it for this purpose the scenarios could highlight the level of services provided and provide a snapshot into how long a condition is likely to remain stable with a certain set of policies in place. Furthermore, key species could be identified and used as an indicator of ecosystem resilience and health - the tool allows a rather flexible selection of species and links those species to ecosystem service provision as some services (e.g. pollination) heavily depend on certain species for their delivery.

As regards monitoring, the tool is primarily useful to monitor the flows of ecosystem services over time and space - provided the right kind of information is provided to the tool. The tool is, however, not suited for monitoring the status of species over time or monitoring the stock of different types of ecosystems over time. It is possible to input data on this in the tool, but the information would need to be already available even without the tool.

The lack of valuation data has proven to be an obstacle for fully using the tool at the national level for adjusting GDP/national wealth for deterioration of ecosystem and biodiversity loss. The InVEST tool has, however, already been used in attempts to adjust GDP/national wealth for lost regulating services, and within this category, in particularly those relating to water. This has been done both for Ecuador and Columbia.

\section{Usefulness to support the implementation of policy, especially land-use decisions}

The tool is useful for modelling potential impacts of specific policy options, and for monitoring the impacts of a specific policy over time as long as you can identify what changes in the land use cover result as a consequence of the policy(-ies). The tool has also frequently been used in land-use planning and in particular for taking into account the ecosystem services when land use decisions are made and, more specifically, the zoning for land-use plans. Here the tool can be used to assess and compare multiple alternative options and it may in particular help identify potential high provision areas. The RIOS (Resource Investment Optimization System) helps in particular to understand in which part of the 
landscape investments in natural capital, including in protection and restoration, will give the greatest returns towards multiple objectives.

The tool does involve putting monetary values on natural resources/ecosystem services and the valuation methods used are tailored to the service that is valued (e.g. for regulation services they use avoided costs - for flood regulation they use avoided flood damage cost; for fisheries they use market values).

The tool addresses the issue of spatial variability of ecosystem services by taking into account both the variability in physical condition as well as the location of beneficiaries and access points (important for some services because there has to be a physical connection between the stakeholders with the flows). It can also account for variability in social preferences. Thus, the flexibility of the tool means that it may incorporate a whole range of locally generated data and is adapted to each country's administrative boundaries.

Robustness, Understandability, Practicability, Credibility, Acceptance Widely published economic/biophysical data is used, but the fact that the models are very simplified also means that it is generally based on the simplest defensible science. The approach's empirical roots are variable depending on the ecosystem service - in the area of water a lot is derived from quiet broad surveys of academic literature, in other areas this is less true. The approach has however proved useful in a wide range of contexts and has already been applied in over 20 policy contexts and every continent, although there has been far more uptake at the city/regional level. In 2013, a free stand alone tool will be released. The developers of the tool are currently in discussion with the World Bank, the American Development Bank, the GEF and USAID.

While the tool is not complicated per se, users have to have some spatial analysis expertise to prepare the models and analyse the outputs which however does not go beyond what is rather common in land use planning agencies. The results are pretty easy to communicate: the information produced is usable in decision contexts and may effectively respond to policy maker's questions. 


\subsubsection{National Ecosystem Assessment (NEA) type approach}

\section{Usefulness to support in problem identification, exploration and policy development}

In its approach, the UK NEA builds, as other similar exercises in Spain and Portugal, on the UN MEA approach. This illustrates that it is quite a flexible approach that can be adapted to each country's administrative boundaries and suggests that it can be a very useful approach in identifying and exploring the challenges a country is facing as regards the management of its natural assets.

While the focus of the approach is on broad ecosystems and their condition, the approach involves looking at the drivers of change. The NEA framework however does not provide a framework for monitoring the use of resources - it is going to primarily establish the links qualitatively and as such highlight the need to develop an improved understanding of adequately monitoring the use of resources that may indirectly result in biodiversity loss. By looking at the drivers of the pressures on biodiversity, it also identifies the economic sectors that are responsible for it. The models that are used as part of such a national ecosystem assessment do not provide methodologies for monitoring substances or pollution harmful to biodiversity, but the NEA is suited for incorporating this into its models. It can to a certain extent act as an early warning system as a core component of it is future scenario building which allow identifying potential future problems. A natural capital asset check is being developed that is being specifically designed to flag up risks to natural capital - so this component will be even further strengthened. The current work also includes clarifying the link between biodiversity/nature and the economy. This helps develop an understanding of how natural capital affects GDP and more specifically, at its core, the approach helps improve the understanding of how different types of ecosystem services (provisioning, regulating, cultural etc.) contribute to the economy. One of the areas that is still being improved here is the consideration of the understanding of the flows of ecosystem services over time to different sectors and end-users in view of improving the understanding of distributional effects. 


\section{Usefulness to support the development of policy-relevant indicators, target setting, reporting and monitoring}

The NEA approach is not really per se an approach to monitor targets at different levels (i.e. local, regional and national) because the approach primarily assembles information generated outside the NEA framework and relies on expert judgement to establish whether trends are going in a worrying direction. One of its contributions as regards monitoring is that it helps identify information gaps that need to be addressed. The NEA approach involves looking at the quality of broad ecosystem types and, if run several times (using the same data and maps) allows for a monitoring of the stock of different types of ecosystems and ecosystem service flows over time. The NEA has been a good framework to discuss the need to adjust GDP for the deterioration of ecosystem and biodiversity loss and to improve the measurement of factors that contribute to human well-being. More specifically, a stream of work has developed in the NEA that aims to better measure cultural ecosystem services and looks into how this information could be included in the national accounts.

\section{Usefulness to support the implementation of policy, especially land-use decisions}

One of the long-term aims is for the NEA to serve as a framework for ranking and prioritising land for the purpose of decision-making and more specifically supporting land use planning that would take into account the ecosystem services provided by land and identifying which pieces of land are important and for which services. This would in turn allow the identification of how to maximise the natural capital value of the land. Currently the problem is that only a limited range of ecosystem services can be modelled and valued.

The NEA has also proven useful for modelling land use change and impacts on ecosystem services under different scenarios. Its purpose is more to act as a modelling tool than to serve as a tool to monitor impacts of specific policies over time. In their modelling a range of modelling tools are used - including the InVest tool - and they are trying to improve these tools in order to allow for an ecosystem service approach. The extent to which monetary values are put on ecosystem services is variable, but the aim is to have monetary values for everything for which it is halfway possible to come up with robust estimates. 
Robustness, Understandability, Practicability, Credibility, Acceptance The NEA is led by academic experts and is based on the best available data and evidence. Where there are gaps in knowledge, there is an element of expert judgement. Overall, the approach can therefore be considered very robust.

While possibly in parts the approach is complicated to communicate to the general public, the approach (as well as its results) is fairly understandable for policy-makers, who are the main target group. The results can be communicated at different levels and in the UK, the NEA exercise has proven to be a powerful communication tool and the results have made it in the news. The graphical representations produced through the NEA can be quite powerful. As a result, the results of the UK NEA have already been used in policy-making. It is also a transparent approach as, with the exception of a limited extent of sensitive and private data - which is restricted in access, the data used is available through UNEP-WCMC.

All in all the NEA approach has proved to be flexible enough in practice to enable it to be used by different countries, including countries with quite different habitat types. One component that is less acceptable and is still at the core of the way the UK has interpreted the NEA approach is the valuation of nature. This is a component that some countries might object to that may or may not be part of such and national ecosystem assessment exercise.

\subsection{Short synthesis}

Table 5.1 below is a synthesis table of the assessment of the different approaches, providing an overview of the specific strengths and weaknesses of each one of the approaches with respect to specific needs expressed by the Nordic Countries. Thus, to a certain extent it might provide insights into which needs expressed by policy-makers each one of the approaches may help address and therefore where the approaches may overall or be complementary/mutually reinforce each other. 
Usefulness to support in problem identification, exploration and policy development (sub-total)

Suitability for identification \& monitoring of use of resources that indirectly result in biodiversity loss

Suitability for identifying economic sector(s) that result in significant pressure on biodiversity

Suitability for monitoring emissions/pollution harmful to biodiversity?

Potential to act as an early warning system

Suitability for establishing links between nature \& the economy (e.g. SNA).

Suitability for demonstrating link between biodiversity \& availability of resources/services important to the economy.

Suitability for improving understanding of how provisioning ESS (e.g. food, timber production) contribute to the economy.

Suitability for improving understanding of how regulating \& cultural services contribute to the economy

Suitability for monitoring the flows of ESS over time to different sectors \& end-users

Does the approach (ac)count for factors that directly contribute to human welfare (e.g. job creation etc.)?

A. Sub-total (problem identification, exploration and policy dev.)

Usefulness to support the development of policy-relevant indicators, target setting, reporting and monitoring

Suitability for setting \& monitoring targets at different levels

Suitability for measuring the quality/resilience of an ecosystem

Use of key species as indicators of ecosystem resilience/health

Does the approach provide a standardised unit for biodiversity?

Suitability for monitoring the status of species over time

Suitability for monitoring the stock of different ecosystems over time

Suitabilty for monitoring the stock of diferent ecosystems over time

Sensitiveness of the approach to seasonal changes in ESS provision

Potential to contribute to development of progress indicator alternative to GDP or adjusting GDP for deterioration of ecosystem and biodiversity loss

B. Subtotal (re policy-relevant indicators, target setting, reporting and monitoring

Usefulness to support to the implementation of policy, especially land-use decisions

Potential to be used to model potential impacts of specific policy option

Potential to be used to monitor impacts of a specific policy over time

Potential to help in supporting land use planning that would take into account ESS (e.g. identification of priority areas for protection/restoration)

Ability to account for spatial variability of ecosystem services

Potential to be used as a framework for combining existing data for spatial planning uses at the local level

Does the approach help put a monetary value on natural resources/ ecosystem services

Inclusion of accounts of spending harmful to biodiversity (and/or EHS)

Adaptability to country's administrative boundaries?

C. Sub-total (support to policy implementation)

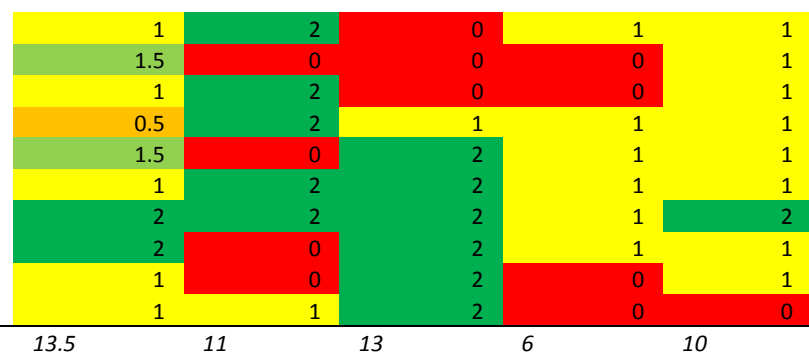

Robustness, understandability, practicability, credibility, acceptance

Does the approach have a sound theoretical base?

Does the approa

Has the approach already been applied in specific (regional/national) contexts/in the real world? Is it, as of today, readily available for use?

Is this approach simple, i.e. easily understandable and easy to communicate?

Do you consider this approach is ready for use in policy-making?

Can the approach be used to tell a story?

Is the approach suited for making all the data available widely?

Is the approach flexible enough to account for the different types of ecosystems while at the same time allowing for international comparisons?

Is the approach internationally accepted and widely endorsed?

D. Subtotal (robustness, understandability, practicability, credibility, acceptance)

TOTAL
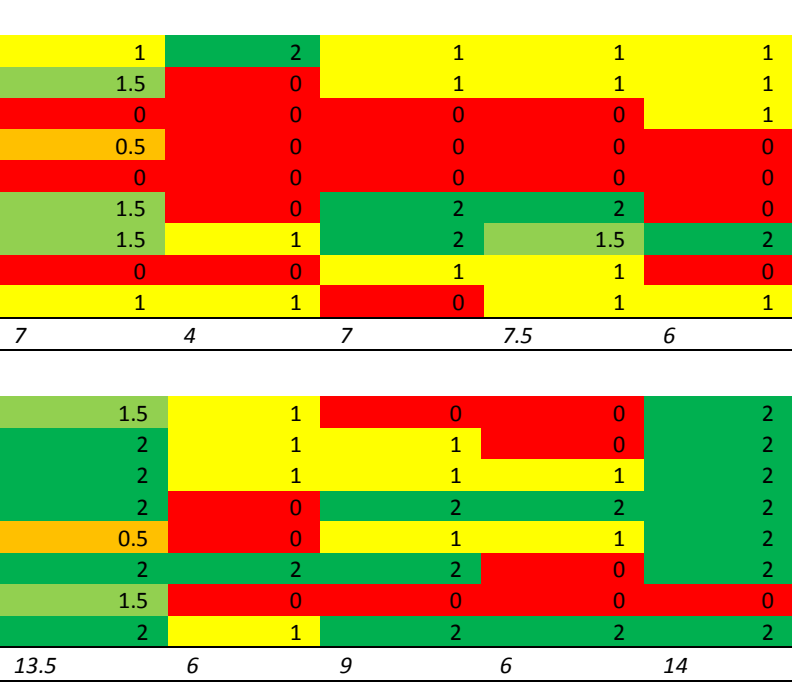

te: Above the valuation is based on 1-2 expert interviews per approach and should be taken as indicative rather than statistical result. Note that this analysis focuses on the current tool rather than potential future planned versions. 
The table above highlights the following findings:

- For problem identification, exploration and policy development, the UK NEA approach has proved very valuable. The MEGS has also the potential to be a very instructive approach but its weakness compared to the UK NEA is that it has so far only been applied to a limited extent. In their current state, the ECA and the InVEST are less informative in the context of the Nordic countries' needs.

- Most of the approaches are not meant to support the development of policy-relevant indicators, target setting, reporting and monitoring in the area of biodiversity conservation or even ecosystem resilience/quality per se. Out of the five approaches, the ECA tool is the one that appears to offer most prospects of providing a basis for the development of indicators to monitor ecosystem resilience/quality, not the least because of its specific (European) focus on ecosystems, but it would take a longer time series and further methodological and data developments to achieve this.

- As regards the implementation of policy, especially land-use decisions, the most policy oriented character of the InVEST tool and the UK NEA means that both approaches score highest out of the five. While the UK NEA is most likely to inform policy implementation at the national level, the InVEST tool has proved useful at the local level - although it might probably have to be adapted to be used in the Nordic context in an optimal way - it could also make sense to integrate the InVest tool further with the specific policy context in the Nordics and in particular impact assessment procedures (EIA and SEA).

- As regards robustness, understandability, practicability, credibility and acceptance, an UK NEA type approach seems to fulfil most criteria. It is based on broad state of the art scientific evidence which it tries to combine in the best possible way. It was possible to put the results of the assessment in formats that made them understandable and appealing both to policy-makers and the wider public - thus generating quite some attention.

The overall scoring suggests that, if it was only possible to adopt one of the approaches, then the UK NEA type approach would probably be the most effective in responding to a wider range of needs expressed by the Nordic countries. It is however also clear from the UK experience that a logical consequence of having carried out the UK NEA has been to strengthen the case for developing natural capital accounting further by implementing the SEEA Volume 1, investing in ecosystem capital ac- 
counting and promoting land use planning tools that help duly take into account ecosystem services in policy decisions at the local and regional levels. The UK NEA has merely helped prioritise activities and is not a substitute to implementing the other approaches to natural capital accounting analysed in the context of this study.

As far as the lower scoring approaches are concerned, the SEEA Volume 1 mostly scores quite low because it does not aim to account for ecosystems and their services per se (this is for other SEEA volumes) and does not provide a basis for spatial analysis of ecosystem service provision that could be relevant in policy-making (something that all the other approaches do). The accounts it provides may prove extremely useful for broader economic analysis, which is why EU Member States are already committed to implementing a whole range of its accounts under European legislation, but its direct applicability for decisionmaking relating to biodiversity is more limited (but still real with some room for improvement, especially if its accounts are better linked with life-cycle impact data on resources and goods which can be linked to specific sectors of the economy within the SEEA framework).

The MEGS and the ECA score lower than the UK NEA because they are both much narrower in scope than the UK NEA and still in the early stages of development - with only limited experimentation on the ground and therefore more limited international credibility. 


\section{Synthesis, roadmap and recommendations}

\subsection{Policy context and needs of the Nordic countries}

The policies and targets related to biodiversity and monitoring of biodiversity are very similar in the Nordic countries. All countries have incorporated or have the ambition to incorporate the biodiversity and biodiversity accounting related Aichi targets in national policies and to set related targets in the NBSAPs that are currently being revised. All have an interest in developing ecosystems accounting and to link this to the economy and to develop methods for valuation of natural capital.

The pressures on the environment, the specific biodiversity related policy targets, their implementation, as well as how these are monitored, slightly differ from one Nordic country to another. In most countries there is a need for monitoring biodiversity as well as the pressures from different economic activities on ecosystems on both a national and local level.

The countries are in various stages of starting projects for developing of ecosystem accounting and valuation of ecosystems or are considering the possibility. In the Nordic countries there seems to be an abundance of ecosystem related data, which is available for different purposes. One of the main challenges in the future seems to be to make data compatible and to link it to spatial mapping to be able to apply ecosystems accounting in a way which would make it useful for different purposes. One such purpose could be to compare different ecosystems in order to be able to rank and prioritise different land areas or ecosystems on the basis of their value, i.e. the ecosystems services they deliver (to complement by insights on biodiversity). A practical application can be local or regional land use decisions (e.g. zoning), where different options for land use are evaluated.

Another could be to make links between ecosystems and the different types of services they provide to each economic sector more explicit. There is especially the need for an increased understanding of different types of provisioning, regulating and cultural services provided by ecosystems and linking their value to the economy and human wellbeing. 
All countries see it as a priority that indicators or accounts should be used as tools for policymaking. They should also be used in monitoring how well the policies are implemented and targets are achieved.

National level biodiversity accounting is in the initial stages of planning in most countries. Today, mostly stocks and flows of natural resources are monitored, mostly on a national level. The views expressed in interviews indicate that a good quality indicator system which monitors ecosystem values would be a desirable solution on a national level. One such example is the Nature Index which is used in Norway.

None of the Nordic countries consider it a priority to develop monetary accounts of ecosystem services or planning with a view to using such values with the specific purpose of adjusting GDP (and accounts of national wealth more generally) for ecosystem degradation and loss of associated capacity to deliver ecosystem services. In addition, this was not seen as practical or feasible as the empirical base would not be considered robust enough and because international standards do not yet exist.

The views expressed in interviews indicate that, on a national level, a good system of indicators to monitor the quality of ecosystems and the trends in the physical provision of ecosystem services over time would be the most practicable way to respond to the various needs of the Nordic countries.

\subsection{The approaches in the light of policy context and needs}

In light of the above policy context, the five approaches to natural capital accounting have been analysed and assessed.

While they all bear the potential to generate information on some of the services provided by ecosystems, each one of the approaches approaches the issue from a different angle and starting point, which results in different strengths and weaknesses when compared to the needs expressed by the Nordic countries.

First, there seems to be a high degree of complementarity between the different approaches. Rather than overlap, they all contribute to an improved evidence base on the services provided by ecosystems and thus make contributions to improving how they are considered in decision-making and national accounting. The UK NEA looks into a very broad range of ecosystem service categories but quite a lot of resources have been invested in developing a better understanding of the recreational value of nature. The SEEA Central Framework can mostly serve to 
capture a range of provisioning services (via flows of natural resources such as fish, timber, minerals, etc) and is not suited to capture regulating, supporting or cultural services. The main strength of the InVEST tool, as things stand today, is its accounting of water related ecosystem services. The MEGS captures a broader spectrum of ecosystem services but at a rather superficial level at present. The current ECA is stronger on carbon biomass, water and land use and their interactions.

Second, the strengths and weaknesses of the approaches need to be seen in the light of the purpose for which they were developed. This means that the approaches are quite complementary and each one of the approaches is very relevant for addressing at least some of the needs expressed by the policy-makers interviewed in the context of this project. However, none of the approaches is really suited for monitoring biodiversity and, with the exception of the expected future ECA, for monitoring ecosystem quality and resilience. This can mostly be explained by the fact that approaches to natural capital accounting are not meant to be used to monitor trends in species, habitats or ecosystem resilience/quality per se - other frameworks have been developed to do this and have already been used and refined for decades. Ecosystem quality or specific species are generally only an aspect that is covered as far as this may inform on the levels of ecosystem services provision or may help model future ecosystem service provision.

Third, to a certain extent, several of the approaches are complementary and may well benefit and reinforce each other, if duly linked. For example, a national ecosystem assessment may be a preliminary stage to identifying the ecosystem services for which it might be worthwhile developing specific accounts to be linked to the national accounts. Furthermore the national approach of the NEA could be complemented by the more local approach of an InVEST type tool at a local level, especially if this tool benefits from targeted efforts to tailor it to the Nordic context that is much more data rich than the kind of contexts the current InVEST tool has been designed to work in. The tool's focus in terms of ecosystem services (water related regulatory services) might not be the right emphasis in the Nordic context.

Fourth, the extent to which priorities are assumed to differ from one country to another determines the extent to which one would recommend that each country may want to focus to varying degrees on each one of the approaches. The methodologies in the SEEA Central Framework can be of use, but it will primarily prove useful for provisioning services and as such has its limitations. Both the ECA and the MEGS aim to develop accounts for a wider range of ecosystem services and for issues currently not covered by the SEEA Central Framework (because there is no internally agreed methodology). Both the MEGS and the InVEST, provide respectively a framework 
and a tool for a clear link to day to day policy-decision at the local or regional levels, the InVEST more specifically providing a tool helping to support spatial planning and natural capital investment decision at the local and regional levels. The MEGS appears quite suited for analysis at the national level, but may well prove less relevant at more local levels.

Fifth, on the monetary evaluation side, the UK NEA approach has included the integration of a valuation module, the MEGS explicitly aims for assessing values for a range of ecosystem services, and the InVEST can be useful for identifying local values, notably around the issue of water. SEEA Vol 1 simply captures market values of goods that are traded, but does not focus on ecosystem services other than selective focus on some provisioning services. The ECA in its current state does not focus at all on monetary values (though one could build on carbon biomass to derive values) and only future ECA development would allow the value/cost of degradation to be assessed, some ecosystem service flows and eventually the costs of environmental debt, domestic and international linked to products (though this is still quite some way into the future).

Finally, all the tools are in principle applicable across different levels of governance and across different types of administrative structures, with perhaps an exception of InVEST that is so far more local, though it has potential for upscaling. The main limitation here is the availability of data in the suitable format and quality to be integrated in the different approaches.

\subsection{Roadmap and recommendations}

Given the emphasis on different aspects within natural capital accounting of each one of the approaches and varying degree in the maturity and experimentation of the different tools, the Nordic countries may want to adopt a strategic approach to developing their natural capital accounting framework broadly following the roadmap summarised in Table 6.1. 
Table 6.1. A summary roadmap for the use of the five approaches within the Nordic countries.

\begin{tabular}{|c|c|c|c|c|}
\hline Approach & Aims / objectives & $\begin{array}{l}\text { Particular strengths/ } \\
\text { added value }\end{array}$ & $\begin{array}{l}\text { Useful short term } \\
\text { actions (0-4 years) }\end{array}$ & $\begin{array}{l}\text { Useful medium term } \\
\text { commitments (5-10 } \\
\text { years) }\end{array}$ \\
\hline UK NEA & $\begin{array}{l}\text { National biophysical } \\
\text { assessment with } \\
\text { monetary "add-on" to } \\
\text { allow selected valua- } \\
\text { tion (e.g. recreational } \\
\text { services) }\end{array}$ & $\begin{array}{l}\text { Very good on problem } \\
\text { identification } \\
\text { Good on supporting } \\
\text { implementation } \\
\text { Easy to understand }\end{array}$ & $\begin{array}{l}\text { Do national NEAs in all } \\
\text { countries and also a } \\
\text { region wide NEA. } \\
\text { Collaboration across } \\
\text { countries to ensure } \\
\text { comparable results. }\end{array}$ & $\begin{array}{l}\text { All countries could } \\
\text { useful to national NEAs } \\
\text { - with regular updates } \\
\text { to help develop a time } \\
\text { series. E.g. every } 5 \\
\text { years / linked to } \\
\text { specific reporting cycles }\end{array}$ \\
\hline $\begin{array}{l}\text { SEEA } \\
\text { Vol.1 }\end{array}$ & $\begin{array}{l}\text { National asset accounts } \\
\text { that link the physical } \\
\text { accounts to the econ- } \\
\text { omy (material flow } \\
\text { accounts, water } \\
\text { accounts etc.) }\end{array}$ & $\begin{array}{l}\text { Understandable } \\
\text { Well developed meth- } \\
\text { odologies } \\
\text { Legal requirement for } \\
\text { EU MS (c.f. EU regula- } \\
\text { tion No 691/2011) }\end{array}$ & $\begin{array}{l}\text { Implementation } \\
\text { already required, } \\
\text { driven by other policy } \\
\text { demands outside of } \\
\text { biodiversity communi- } \\
\text { ty. }\end{array}$ & Make a standard tool. \\
\hline MEGS & $\begin{array}{l}\text { Mapping of ecosystem } \\
\text { types and selected } \\
\text { ecosystem services } \\
\text { across national territo- } \\
\text { ry with work ongoing } \\
\text { on how to attribute } \\
\text { monetary values }\end{array}$ & $\begin{array}{l}\text { Good for exploring links } \\
\text { of economy and } \\
\text { ecosystem service } \\
\text { flows. }\end{array}$ & $\begin{array}{l}\text { Wait until the current } \\
\text { tool development is } \\
\text { completed and experi- } \\
\text { ment with the ap- } \\
\text { proach, helping clarify } \\
\text { how it would benefit } \\
\text { the NEA exercise }\end{array}$ & $\begin{array}{l}\text { Use aspects of the } \\
\text { approach that are } \\
\text { useful within the } \\
\text { overarching NEA type } \\
\text { approach }\end{array}$ \\
\hline ECA & $\begin{array}{l}\text { Physical accounts for } \\
\text { land use types, carbon } \\
\text { biomass and water. } \\
\text { Value aspects (degra- } \\
\text { dation and services) } \\
\text { not within current ECA }\end{array}$ & $\begin{array}{l}\text { Quite good indicators } \\
\text { development, especial- } \\
\text { ly on links between } \\
\text { land use, carbon } \\
\text { biomass and water. }\end{array}$ & $\begin{array}{l}\text { Do national experimen- } \\
\text { tation as this will help } \\
\text { mature the tool and } \\
\text { realise its potential - } \\
\text { liaise with EEA and also } \\
\text { engage with WAVES. }\end{array}$ & $\begin{array}{l}\text { Generalise application } \\
\text { where experimentation } \\
\text { suggests particular } \\
\text { added-value }\end{array}$ \\
\hline InVEST & $\begin{array}{l}\text { Local spatial biophysi- } \\
\text { cal assessment and } \\
\text { includes a value } \\
\text { module for selective } \\
\text { services (mainly water } \\
\text { related) }\end{array}$ & $\begin{array}{l}\text { Good for modelling } \\
\text { impacts of different } \\
\text { policy options and } \\
\text { support local imple- } \\
\text { mentation especially as } \\
\text { regards water }\end{array}$ & $\begin{array}{l}\text { Adapt InVEST in specific } \\
\text { Nordic context (esp. } \\
\text { data availability and } \\
\text { most relevant ESS) and } \\
\text { encourage local exper- } \\
\text { imentation }\end{array}$ & $\begin{array}{l}\text { Make the adapted tool } \\
\text { widely available as well } \\
\text { as supporting data and } \\
\text { encourage local appli- } \\
\text { cations }\end{array}$ \\
\hline
\end{tabular}

In a roadmap to implement their commitments relating to natural capital accounting the first step for the Nordic countries will be to identify the areas where the development of accounts could be of particular importance and could help in designing effective biodiversity policy. The goals of the policy is to address the pressures and the drivers of biodiversity loss and thus to address some of the root causes behind the deterioration of ecosystems. Approaches that would help assess the state of ecosystems and identify the reasons behind negative trends in their overall stock and quality would likely identify the economic sectors whose production methods need to be changed in order to reduce the pressures on biodiversity. Natural capital accounting can make a contribution in identifying both the ecosystems that are most under stress, the ecosystem services 
that are at risk of being lost, and which sectors bear most responsibility in the deterioration of the different ecosystems under scrutiny.

Out of the different approaches analysed in the context of this study, the UK National assessment seems to bear most potential to provide this kind of information and thus to respond to the Nordic countries' information needs. It has however a whole range of weaknesses in key areas that would justify that the Nordic countries engage with each one of the approaches analysed in this study in some way or another. While the UK NEA-type approach appears one of the most useful in the short run and should help target further natural capital accounting efforts on areas of highest added value, the development of some of the approaches in the short term appears unavoidable and indeed essential given broader benefits to policy making as a whole (e.g. SEEA Central Framework).

Irrespectively of the approach chosen, however, the Nordic countries will have to invest into making the approaches their own, adapting them to their specific ecosystems and data availability. In developing a strategy for the future the Nordic countries should ensure that work on different accounting approaches is not carried out in isolation and that no opportunity is missed to interlink the initiatives so they may mutually reinforce each other to form a coherent whole that helps address the challenge of integrating biodiversity across sectors and society as a whole at multiple levels of governance.

It is clear that given the need to make swift progress in this agenda the Nordic countries should ideally cooperate to ensure due progress in the different areas. Especially as far as the more experimental and less mature approaches to natural capital accounting are concerned (ECA, MEGS, adaptation of the InVEST tool to the Nordic context) it would be best if the Nordic countries could share the burden of developing and adapting the approaches to the Nordic countries. The Nordic countries could develop the tools in parallel in view of making them available to all Nordic countries to use once they have passed the experimental stage. Some countries would therefore be particularly engaged in the global context to feedback experience from the international context into the Nordic context - but also in view of having other countries outside Europe benefit from the Nordic experiences. This process has indeed already started with Norway's involvement in the WAVES initiative, which might soon be joined by Sweden. 
Given the level of complexity of Natural Capital Accounting but also the different reasons there might be to engage in such an exercise, it would be worthwhile for the Nordic countries to consider setting up a Nordic group of experts specialised in ecosystems accounting to draw a more detailed roadmap for the future (noting commitments and responsabilities), regularly meet and share experiences and relevant information. This would be especially useful for those countries which are in the initial stages on assessing for instance how to include nature values in national accounting. In the Nordic forum there are formal groups, such as MEG or TEG, but it may be worth considering increasing cooperation and sharing experiences on natural capital accounting more specifically. If a specific group were set up this could avoid unnecessary duplication of efforts in making progress in the development of methodologies and experimentation as well as linking with other international experimentations (e.g. WAVES).

As far as the composition of such a group is concerned, while it appears it would be useful that CBD focal points be involved to ensure due focus and links to the biodiversity policy agenda, it would be key that other parts of the government administration and the statistical offices be involved as well. This ensures the support and resources made available to the work and that a common understanding of the potential uses of natural capital accounts is developed. One example to look for in this context is the UK Natural Capital Committee that was set up in the wake of the publication of the results of the UK NEA. Ecosystems valuation and natural capital are relatively new concepts at least in their practical application. Developing a practical exchange of ideas on good ways of implementing and finding standards which would apply in a Nordic context could be valuable.

Finally, data compatibility has been identified as an issue which could be improved. As monitoring is further developed, it should be kept in mind that collected data should be comparable and of the same quality to enable comparing similar ecosystems or prioritising land use using similar metrics across the Nordic countries. Also consideration should be given to implementing open source thinking for the data across the Nordic countries, possibly via a dedicated website that would provide all statistics, accounts and potentially even decision-making support tools that would result from an implementation of the natural capital accounting approaches. Indeed, the data to be generated by natural capital accounting approaches can be of use not only to policy-makers but also businesses that might want to evaluate their exposure to certain risks related to resource scarcity or reduce their impacts on biodiversity 
through their supply chain. Other target groups could be researchers and universities. Similarly, developing an approach such as the InVEST tool to allow for a better consideration of ecosystem services in decisionmaking at the regional and local level, in line with existing requirements in the area of environmental impact assessment, and to be adapted for use in the Nordic context, could be useful. 


\section{Sammanfattning}

Rapporten utvärderar styrkorna och svagheterna av några av de mest framstående internationella metoderna för redovisning av naturkapital, i hänsyn till de politiska mål, institutioner och villkor som finns i Norden. Rapporten granskar inte bara olika metoder som utvecklats för att inkludera biologisk mångfald och ekosystemtjänster i nationalräkenskaperna, utan tar ett bredare perspektiv.

De policies och de målsättningar som berör den biologiska mångfalden och dess uppföljning är mycket lika i de nordiska länderna. Samtliga länder har i sina nationella policies inkluderat eller har ambitionen att inkludera bevarandet av den biologiska mångfalden och de uppsatta Aichi målen, som berör redovisning av biologisk mångfald. Man planerar att inkludera målen i de nationella strategierna och handlingsplanerna som berör bevarandet av den biologiska mångfalden (NBSAP), som håller på att bearbetas.

Alla nordiska länder anser att indikatorer eller redovisning (accounts) ska aktivt användas som verktyg för beslutsfattande. De bör också användas i uppföljningen av hur väl de politiska besluten och de förknippade målen genomförs både på lokal och nationell nivå. Samtliga länder har ett intresse av att utveckla värdering av ekosystemtjänster och att koppla detta till ekonomin samt att utveckla metoder för miljöräkenskaper.

Redovisning av biologisk mångfald på nationell nivå är i ett inledande skede i flesta nordiska länder. För tillfället uppföljs framförallt "lager" och flöden av naturresurser. Intervjuerna som utförts i samband med rapporten indikerar ett behov för pålitgliga indikatorer och räkenskapssystem för värdering av ekosystemtjänster, speciellt på nationell nivå. Monetär värdering och justering av BNP på nationell nivå ses däremot inte som en prioritet, innan det existerar generellt accepterade internationella standarder för hur detta skall implementeras.

De internationella metoderna som granskats i studien utgör försök att skapa en bättre kunskapsbas om sambanden mellan biologisk mångfald och ekosystem å ena sidan och ekonomin och människors välbefinnande å andra sidan. Det gemensamma målet för metoderna är att kunna ge bättre beslutsunderlag till beslutsfattare i olika sammanhang. De fem metoderna som valts för en mer djupgående analys är: 
- SEEA Central Framework (SEEA Volume 1).

- EEA's simplified Ecosystem Capital Accounts (ECA).82

- Kanadas Measuring Ecosystems Goods and Services (MEGS).

- Britanniens National Ecosystem Assessment (UK NEA).

- Integrated Valuation of Ecosystem Services and Tradeoffs eller InVEST.

Alla de granskade metoderna kan generera information om vissa ekosystemtjänster. Metoderna närmar sig dock frågan från olika håll och olika utgångspunkter. Detta resulterar i olika styrkor och svagheter, när man utgår från de nordiska ländernas behov (se kapitel 4).

I stället för att överlappa, kompletterar metoderna varandra och bidrar till en förbättrad kunskapsbas om de tjänster som ekosystemen producerar, vilket kan användas som grund för beslutsfattande och bättre nationalräkenskaper. Den brittiska metoden NEA ser på ett brett spektrum av kategorier av ekosystemtjänster. Mycket resurser har investerats i att utveckla en bättre förståelse för till exempel miljöns rekreationsvärde. SEEA kan oftast användas till att identifiera direkta försörjande tjänster, som till exempel materialflöden, som ekosystemen levererar. Den lämpar sig däremot inte till att lyfta fram mindre konkreta (indirekta), reglerande, upprätthållande eller kulturella ekosystemtjänster. Den främsta styrkan som InVest verktyget i nuläget har är, att den möjliggör redovisning av vattenrelaterade ekosystemtjänster. MEGS i sin tur fångar ett bredare spektrum av ekosystemtjänster, men tillsvidare på en ganska ytlig nivå. ECA är starkare på att tydliggöra förändringar till exempel i biomassa (samt dess roll i att ta upp och lagra koldioxid), vatten samt markanvändning och deras interaktioner.

Samtliga metoder som granskades är relevanta ur ett nordiskt perspektiv. Tillsammans uppfyller de flera kriterier och svarar på flera behov som nämndes i intervjuerna. Däremot, är ingen av de granskade metoderna egentligen särskilt lämpad till uppföljning av den biologiska mångfalden och, med undantag av framtida ECA, inte heller för uppföljning av ekosystemens kvalitet och resiliens.

Det är livsviktigt att man kan utarbeta effektiva policies som tar itu med påverkansafaktorer och drivkrafter som ligger bakom utarmningen av biologisk mångfald. För att genomföra de åtaganden som berör redovisning av naturkapital, borde de nordiska länderna under de närmaste

82 Specifically the approach to implementing the central framework promoted by the World Bank's WAVES project, which promotes the use of the central framework to incorporate natural capital into national accounts. 
åren identifiera områden där utvecklandet av redovisning kan ha särskild betydelse och bidra till att de uppsatta målen nås.

Av de metoder som granskats i rapporten verkar den brittiska metoden NEA bäst svara på de nordiska ländernas informationsbehov. Den har emellertid vissa svagheter i viktiga områden. Det kan därför vara motiverat att de nordiska länderna på ett eller annat sätt samarbetar med varandra för att vidare utveckla de metoder som analyserats, så att de bättre kan tillämpas i de nordiska länderna. Även om NEA på kort sikt är en av de mest användbara metoderna, verkar det oundvikligt och nödvändigt ur ett nordiskt perpektiv att man också utvecklar några av de andra metoderna. De kan eventuellt bidra till en bättre helhetsbild och bidra till mera effektiva policy processer (t.ex. SEEA Central Framework). Oberoende av vilken eller vilka metoder som man utvecklar, måste de nordiska länderna investera i att anpassa dem till sina specifika förhållanden samt satsa på att säkra informationens tillgänglighet.

Det skulle också vara bra att säkra att den underliggande informationen (data) är kompatibel för att möjliggöra att den kan utnyttjas i olika sammanhang. Det "öppna data tänkandet" kan medverka till att datat utnyttjas också för andra nyttiga ändamål. Informationen kunde till exempel utnyttjas av företag för att utvärdera och minska sin verksamhets risker och konsekvenser på miljön.

Rapporten identifierar flera möjligheter för nordiskt samarbete gällande värdering av ekosystemtjänster och redovisning av naturkapital. Nordisk nytta kan identifieras särskilt beträffande samarbete om de mer experimentella och mindre etablerade metoderna för redovisning av naturkapital. Det kunde även vara nyttigt att etablera ett särskilt forum för samarbete i dessa frågor - en nordisk expertgrupp som är specialiserad på ekosystem. Gruppen kunde skapa en roadmap för framtiden, träffas regelbundet för att utbyta erfarenheter och relevant information. 



\section{Annex 1 ECA}
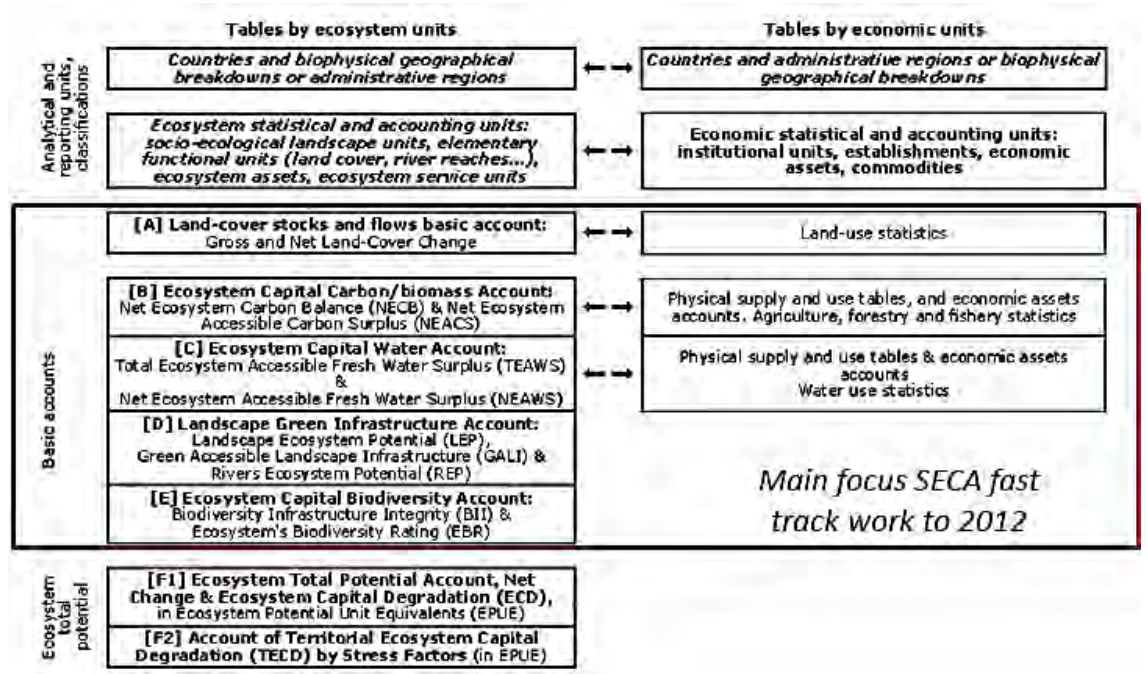

[G] Demand and Accessibility to Ecosystem

Ecosystern Carbonibiomass, Ecosystem Fresh Water,
Green Infrastructure Neighbourhood Ecos rystem Services

[H] Ecosystem Physical Balance Sheet: Stocks and Change of Nan-Financial and Finäcial Assets \&
Physical Liabilities, in EPUE

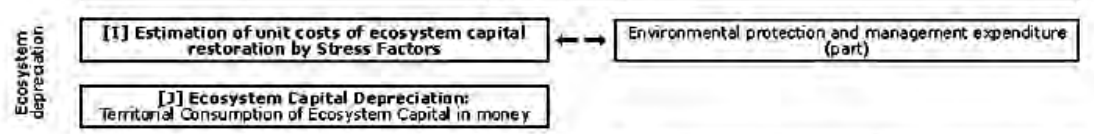
[K] Account of Ecosystem Capital Degradation \&;
Depreciation Embedded into Imports and Exports,
in EPUE and in moner

Ecologically Sustainable Ecosystem Services Macro-economic Benefits
Suble Total Induced Value Added (ES-TVA) (by SELU and ISIC)

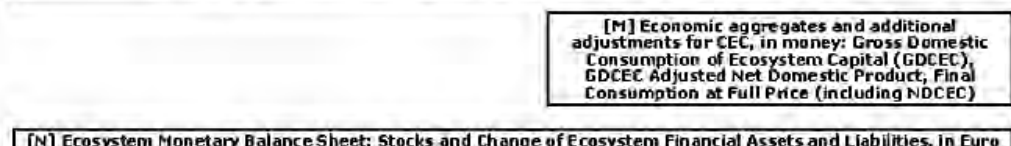

[N] Ecosystem Monetary Balance Sheet: Stocks and Change of Ecosystem Financial Assets and Liabilities, in Euro 


\section{Natural Capital in a Nordic context}

The report reviews different international approaches for natural capital accounting. The five approaches reviewed are attempts to help create an improved evidence base on the links between biodiversity and ecosystems on the one hand and economic and human wellbeing on the other in view of better informing decision-making in a variety of contexts. The strengths and weaknesses of the approaches are evaluated in the light of the policy goals, institutions and conditions in the Nordic countries.

The analysis has been carried out during the period September 2012 - January 2013 by Gaia Consulting Oy and the Institute of European Environmental Policy. The project was commissioned by the Nordic Council of Ministers. 
Nordic Council of Ministers

Ved Stranden 18

DK-1061 Copenhagen K

www.norden.org

\section{Natural Capital in a Nordic context}

Status and Challenges in the Decade of Biodiversity

The report reviews different international approaches for natural capital accounting. The five approaches reviewed are attempts to help create an improved evidence base on the links between biodiversity and ecosystems on the one hand and economic and human wellbeing on the other in view of better informing decision-making in a variety of contexts. The strengths and weaknesses of the approaches are evaluated in the light of the policy goals, institutions and conditions in the Nordic countries.

The analysis has been carried out during the period September 2012 - January 2013 by Gaia Consulting Oy and the Institute of European Environmental Policy. The project was commissioned by the Nordic Council of Ministers. 